\title{
Climate security and a vulnerability model for conflict prevention: a systematic literature review focusing on African agriculture
}

\author{
Daniel Pearson * (D) and Peter Newman
}

\begin{abstract}
Background: Climate change poses credible threats to the livelihoods of many. This paper addresses how climate change adaptation can help counter the increased risk of violent conflict that is associated with these climatic changes. Extant climate-conflict links however, involve a complex interaction of many factors that mediate the impact of climate change. Thus, adaptation methods should not focus simply on the direct impacts of these changes.

Methods: This paper, using the Systematic Literature Review method, conducts an analysis of the climateconflict and climate adaptation literature covering 46 papers, with a geographical restriction of Africa and focusing on the quantitative comparative literature.

Results: This SLR had two key aims, first to understand how links and common areas of understanding between the climate-conflict and climate adaptation fields of research could inform future empirical quantitative research into the notion of climate adaptation as conflict prevention. And secondly, how future quantitative comparative climate conflict research could be informed. It suggests a Vulnerability Model that assists in understanding how vulnerability, understood through the lens of exposure, sensitivity and adaptive capacity, can provide researchers and policy makers with the various factors, both direct and indirect, which can identify where violent conflict might occur. Simultaneously, it illustrates what factors influence the adaptation needs of an agricultural community and hence how adaptation could reduce the risk of future violent conflict. Future quantitative comparative climate-conflict research could also benefit by using disaggregated sub-national data, focusing on agricultural communities using variables that draw on the Vulnerability Model.
\end{abstract}

Keywords: Climate change, Adaptation, Violent conflict, Vulnerability

\section{Background}

Within the last decade there have been rising concerns about the negative effects of climate change. Such changes could result in increasing rates of violent conflict among vulnerable communities [26]. Discourse surrounding this concern has seen much attention from politicians and other public commentators. Prominent examples include former President Barack Obama speaking at the United Nations (UN) in 2009, asserting that the threat posed by climate change was serious,

\footnotetext{
* Correspondence: daniel.g.pearson@graduate.curtin.edu.au Curtin University Sustainability Policy Institute (CUSP), Building 209, Room 133, Kent St, Bentley, WA 6102, Australia
}

growing and would lead to more hunger and conflict [43]. Other prominent United States security officials, such as former US Defence Secretary Chuck Hagel, have raised concerns about climate change acting as a threat multiplier contributing to greater conflict risk.

However, the quantitative comparative literature is yet to settle on a consensus as to the definitive causal mechanisms linking climatic changes to violent conflict [10]. The research continues to search for clear links as to where, how and when one can expect causal links in this climate-conflict debate. As it stands, the little consensus that exists sees any links as being indirect and mediated

(c) The Author(s). 2019 Open Access This article is distributed under the terms of the Creative Commons Attribution 4.0 International License (http://creativecommons.org/licenses/by/4.0/), which permits unrestricted use, distribution, and reproduction in any medium, provided you give appropriate credit to the original author(s) and the source, provide a link to the Creative Commons license, and indicate if changes were made. The Creative Commons Public Domain Dedication waiver (http://creativecommons.org/publicdomain/zero/1.0/) applies to the data made available in this article, unless otherwise stated. 
by a number of social, political, economic and other factors [10]. Considering this, settling on precise and reliable conflict prevention ${ }^{1}$ initiatives, with a focus on climatic and environmental variables, would be ill advised due to the lack of consensus in the evidence base. Yet, climate adaptation is known to have the potential for reducing the negative impacts of climate change, and thus could be a viable option ${ }^{2}$ for the prevention of violent conflict as well.

The UN describes adaptation as involving the reduction of risk and vulnerability; seeking new opportunities and building the capacity of nations, regions, cities, the private sector, communities, individuals and natural systems to cope with the adverse impacts of climate change (Huq et al. [40]). In the climate-conflict literature, there is a high level of agreement in understanding how the agricultural sector may be part of any extant causal links. This is particularly the case where, in Africa for example, there is a high level of dependence on rainfed agricultural practices $[22,27,54]$. Authors in the climate-conflict literature have illustrated the need for appropriate adaptation in this sector to ensure resilience and to contribute to conflict prevention in the face of climate change ([18, 60]; [13, 23]). Vivekananda et al. [57] stress "the need to understand the linked conceptual pairs of fragility and stability, vulnerability and resilience, and human security and insecurity, in order to analyse the pathways between climate change and violent conflict or peace." One suggestion Vivekananda et al. [57] make is to ensure that climate adaptation is peace positive, contributing to building resilience among fragile and vulnerable communities.

In contributing to the broader and expanding field of climate security, a Systematic Literature Review (SLR) has been conducted to provide an overview of how the literature on climate-conflict and climate adaptation are linked. It is designed so that understanding these links and overlapping areas of research between these two fields, can assist in understanding how future research into climate adaptation as conflict prevention should progress. By focusing on the quantitative literature in fulfilling these two key aims, it is expected that the results will be quantitative in nature suitable for empirical testing, and thus best suited for informing future generalizable empirical research.

This SLR analyses the literature in both the climate-conflict, and climate change adaptation fields of research, with two key research aims. First is to understand what informative links exist between these two fields of research, and how any such links could inform future research into climate adaptation as conflict prevention. It focuses on the African continent, but its conclusions are not necessarily confined to this sector and geography.
Concerning this geographical focus, there is evidence for what is termed 'the streetlight effect' in the climate-conflict literature [2]. This effect describes selection bias that afflicts the quantitative research focusing on this continent, however this review does not generate a new statistical analysis but reviews the state of the literature as it exists. Thus, this bias cannot be entirely avoided until afflicted quantitative studies and research methods have been remedied. None the less, such a geographical focus is not unwarranted, as this continent is regarded as perhaps the most sensitive and vulnerable to the impacts of climate change [26]. There is also broad agreement on this consensus in both the climate adaptation and climate conflict literature, as will be noted in the body of this review.

The second key aim is to assess how what is found in this SLR could inform the quantitative comparative climate-conflict literature, finding a robust and statistically significant causal link between climate change and violent conflict. As such, it is not the primary aim of this SLR to assess the validity of the claim that climate change may contribute to an increase in violent conflicts (though the second aim contributes to this literature as will be explored in the body of this paper). However, this SLR finds support for, and confirms, the broad consensus reached thus far: that any climate-conflict links are likely mediated by a number of socio-political and economic factors.

\section{Methodology}

The purpose of this SLR was to identify links between the two mentioned fields of research, and specifically to provide direction on how research on 'climate adaptation as conflict prevention' should progress. With the second aim of informing future quantitative comparative climate-conflict research. To this end, the review will, to a lesser extent, evaluate the fields of research separately. The primary goal is to evaluate them so that shared patterns, areas and links in the research can inform the aims of this SLR.

The SLR methodology has seen most of its development in the health and medical sciences, yet it is being more frequently applied to other fields of research to assist in the revision of large and sometimes unmanageable amounts of data [16]. Through its rigorous and systematic methodology, bias that often afflicts the narrative method is minimized, whilst a general overview is attained with the assurance of transparency and replicability [35].

This SLR will follow the five steps outlined by Denyer and Tranfield [16]: i) defining the problem and research topic; ii) identifying the relevant studies; iii) selecting the 
studies; iv) the data synthesis; v) and summarising and discussing the results.

\section{Problem definition}

The purpose of this SLR is to review the literature on climate change and violent conflict (climate-conflict nexus) and climate change adaptation (climate adaptation) to uncover links between the two fields. Specifically, the aim is to discover how such links might inform future research and perhaps policy on how climate adaptation can contribute to the prevention of violent conflict.

\section{Identification of relevant studies}

With this problem definition in mind, the next step was to perform a search of relevant, multidisciplinary scientific databases using a defined search string with relevant keywords. Here, it is also important to note that the following methodology was carried out for both fields of literature separately. For this study, four high impact international databases were used: Scopus, Web of Science, Science Direct and Google Scholar.

\section{Climate-conflict nexus}

There were two key areas to be investigated, that of 'climate change' and 'violent conflict', each had several variations (see Table 1 below). There is also a geographical focus for this review: Africa, however, this key word and variations were not included in the search string (studies including Africa but with a global focus were excluded). This is since most empirical climate-conflict research has been conducted focusing on Africa and this research field in itself is not too large that excluding the term 'Africa' did not result in the retrieved articles becoming unmanageable. These queries had no timelines applied and were only searched using the 'article title', as including the abstract expanded the results, in Scopus for example, by over seven thousand. Another important caveat was that Web of Science produced over three hundred thousand results for the search string in Table 1. Thus, the search term used was simplified to produce manageable results: (climate AND conflict).

Table 1 Below are the various keywords used in the search string

\begin{tabular}{ll}
\hline Key search areas & Search string with alternative keywords \\
\hline Climate change & climate $^{a}$ OR variability ${ }^{a}$ OR warming \\
Violent conflict & conflict $^{\text {a }}$ OR war ${ }^{a}$ \\
\hline
\end{tabular}

Words with an asterix ${ }^{(\mathrm{a})}$ indicate alternative variations used

\section{Climate adaptation}

The same four databases were used to assess the literature in this area. The key areas to be investigated were 'climate change' and 'climate change adaptation', this time including 'Africa' as a search term. Including 'Africa' in this search string was important as the literature on climate adaptation is far greater. Excluding Africa, in Scopus for example, increases the results by over four thousand. There were no timeline restrictions and search strings were only applied to the article title for the same reason mentioned for the climate-conflict search (see Table 2). An important note applies for this search string in the Web of Science database as well, which produced results that were over two hundred thousand, thus the simplified search string for this data base was (climate AND adaptation AND Africa).

\section{Selection of studies}

Once all the articles had been retrieved from the databases, they were collected and sorted by date for both fields of research. Conducting an exhaustive review was not the aim of this paper, thus two overarching criteria were applied to both searches in the literature. First was including only peer reviewed journal articles and book chapters, not grey literature. Simultaneously, literature that was comparative and quantitative was a further selection criterion for both research fields. The idea of focusing on the quantitative literature is not to do a quantitative meta-analysis employing statistical methods in the analysis, but the analysis is qualitative in nature whilst quantifying basic elements of the literature. Such literature allows for greater capacity to generalize for variables and links across regions and case studies, whilst also providing statistical significance [8]. Here, comparative was defined as comparing two or more countries, whether they used data at the national or subnational level. Quantitative was seen to analyse results using data that utilized statistical methods and various types of modelling, such as regression analyses. Whilst there is the above stated benefit of focusing on quantitative comparative studies, there is also reason to include single case quantitative studies for the climate conflict literature. Most quantitative comparative studies in the climate-conflict literature are designed at the national level and can therefore

Table 2 Below are the keyword variations, where the asterix $\left({ }^{*}\right)$ indicates the alternate endings

\begin{tabular}{ll}
\hline Key search areas & Search strings with alternative keywords \\
\hline Climate change & climate* OR variability* OR warming* $^{*}$ \\
Climate adaptation & adaptation* OR adapt* $^{*}$ \\
Africa & Africa* OR Sahel $^{*}$ \\
\hline
\end{tabular}


overlook important subnational dynamics [30]. This was not necessary however for the climate adaptation literature as most such studies have a subnational research design in their comparative studies. Through this process it is unlikely that all relevant articles will be found, and because this methodology should be followed without deviation in order to enable consistency with other such SLR's, a small number of articles may not have been included in the final selection.

\section{Climate-conflict nexus}

Duplicates were highlighted (for ease of selection) but not removed, as some results shared the same title yet had different authors. Some retrieved papers addressed climate change yet did not have that term in the title (rather containing, for example, 'warming' and 'drought'). Thus, it became important that the abstracts of the results were also screened on the basis that they addressed causal links between climate change and violent conflict, keeping in mind both quantitative single case studies and quantitative comparative criterion, focusing on Africa.

\section{Climate adaptation}

Similarly, duplicates in the climate adaptation literature were highlighted rather than deleted. Titles and abstracts were screened for evidence of adaptation in response to the adverse effects of climate change, whether they were perceptions, actual adaptation methods taken or otherwise. Those that did not address these two-key criteria, containing a quantitative comparative analysis with a focus on Africa, were excluded.

For both fields of literature, the article titles were initially screened to remove those that were clearly irrelevant on the basis of the geographic focus or by the topic covered. Secondly, the abstracts were then screened in accordance with the criteria outlined previously, this process was then repeated including screening of the introduction and the body of the text if need be to ensure an accurate inclusion of relevant articles. See Tables 5 and 6 for further details.

It is worth noting the justification for conducting the SLR on the two mentioned fields separately, excluding three sets of literature, first is the exclusion of a search on 'climate adaptation as conflict prevention' for example. The notion of the prevention of violent conflict, conflict that is seen to relate to climate change, through climate adaptation, is a new and developing field, where there is a sparse amount of literature to assess. A preliminary search string (climate AND adaptation AND conflict OR war AND prevention OR prevent) that was applied to the abstract, key words and title in Scopus for example, revealed only thirty-seven results. Of these only five had any relation to climate change, adaptation and the prevention of violent conflict. Second is the exclusion of the environmental peacebuilding literature. A title search string (environmental AND peacebuilding) in SCOPUS revealed less than 100 results. Of these, those that are empirical are most often single case qualitative studies, as already noted above, we argue that the aims of this SLR are best met by empirical quantitative studies. The empirical research in the environmental peacebuilding literature is arguably inconclusive and still in development [24]. As such, we argue that a separate review of the environmental peacebuilding literature to review the state of knowledge as it stands in that field, would reveal more relevant knowledge than this review and its aims. Third, is the exclusion of the qualitative literature. For this paper, in line with the two key aims, we hope and expect to generate results that are suitable for empirical quantitative testing and that are generalizable across space and time, considering this a focus on the quantitative and comparative literature is justified. Thus, the decision was taken to present a fresh approach whilst illustrating how research into climate adaptation as conflict prevention should progress. It is hoped that by making this choice a contribution to new knowledge can be gained from this SLR.

The initial search for the climate-conflict literature found a total of $\mathbf{1 7 3 2}$ results, and for the climate adaptation literature there was a total of $\mathbf{1 0 8 0}$ results, a combined result of 2812. See the final list containing all retrieved articles after final selection in the appendix. These were then refined down to a final 27 on climate-conflict and 19 on climate adaptation through the filtering mechanisms shown in Tables 3 and 4.

Tables 3 and 4. Search results updated between 15th and 20th February 2018.

Table 3 Climate-conflict results

\begin{tabular}{ll}
\hline Databases. & Results \\
\hline Google Scholar & 894 \\
Scopus & 486 \\
Web of Science & 260 \\
Science Direct & 92 \\
Total & 1732 \\
Filter through article title & $n=1178$ \\
Initial filter through abstract & $n=55$ \\
Second filter through abstract and introduction & $n=27$ \\
Final count after selection & 27 \\
\hline
\end{tabular}


Table 4 Climate adaptation results

\begin{tabular}{ll}
\hline Databases. & Results \\
\hline Google Scholar & 798 \\
Scopus & 156 \\
Web of Science & 98 \\
Science Direct & 28 \\
Total & 1080 \\
Filter through article title & $n=854$ \\
Initial filter through abstract & $n=40$ \\
Second filter through abstract and introduction & $n=19$ \\
Final count after selection & 19 \\
\hline
\end{tabular}

\section{Data synthesis and summary of results}

The synthesis of data involves aggregating the articles and their findings to obtain a general overview of the field(s), whilst also relating information and patterns across the studies that would not be clear from reading the individual texts [16]. Analysis and selection of data relies to some extent on the subjective interpretation of the author, indicating infiltration of bias which is a weakness of the SLR method, yet, this methodology only minimises bias as opposed to eradicating it [35].

For both fields of literature, all papers were classified, and data extracted according to their scale of analysis (national/sub-national), non-climatic variables and climatic variables measured, effect on conflict risk and effectiveness of adaptation methods, group type studied, analysis of vulnerability among several other relevant categories. Although most of the data was used in some form or another (in the creation of the various figures for example), the categories in Tables 5 and 6 were drawn from this larger set of data points and were used for the core of the analysis as we posit they best inform the two aims of this paper ${ }^{3}$. Appendix provides a small sample of the categories created that informed the basis for Tables 5 and 6, land how further analysis based on Tables 5 and 6 was generated. These aims do not necessitate an analysis which focuses on specific methods of quantification, variables and model specifications. Indeed at least one SLR has already been conducted for such purposes for the climate-conflict nexus, for example see Sakaguchi, Varughese and Auld [45]. To this end, this SLR is less focused on providing a traditional, overview of the fields as usual when conducting the SLR method. Rather, the focus is on drawing out key links between the two different fields of literature, and on the informative value for the aims of this paper. It is hoped that this approach will provide some sense of research and policy outcomes for environmental peace-building and conflict prevention, rather than just describing the field.

\section{Result synthesis \\ Climate-conflict results \\ Group/land use type studied}

A variety of groups and conflict types are identified in the literature, however, strict classification was difficult as the groups analysed are not always definitively stated. For example, broad mention may be given to rain fed agricultural communities in sub-Saharan Africa being the most vulnerable to the effects of climate change [13]. It is such cases that can make for some ambiguity, none-the-less, classification was still achieved. Indeed, Raleigh and Kniveton [42] assert that past studies have failed to separate conflicts into different groupings according to their structures, aims and goals. It may also be that strict mention not always being made of such groups, was not the aim of the quantitative comparative literature, rather it enables researchers to generalize across regions for factors linking climatic changes to conflict [10]. To gain clarity on this issue guidelines for classification were taken from and found to be like that of Raleigh and Kniveton [42]. They document rebel conflict, involving rebel groups and the state, as well as

Table 5 Classification of articles into four selected categories for the climate-conflict nexus

\begin{tabular}{ll}
\hline Category & Description \\
\hline Land use/group studied & $\begin{array}{l}\text { Groups that were involved in instances of violent conflict } \\
\text { (ranging from state actors to local communities). }\end{array}$ \\
Vulnerability relating to climate change & $\begin{array}{l}\text { Understanding how subjects studied are vulnerable to climate } \\
\text { change and thus, potentially, to violent conflict. }\end{array}$ \\
Vulnerability relating to other factors (excluding climate change) & $\begin{array}{l}\text { Understanding the multiple variables other than climate change, } \\
\text { that contribute to such vulnerability and thus the potential for conflict. }\end{array}$ \\
& $\begin{array}{l}\text { Recommendations for peacebuilding efforts, hence, how to reduce } \\
\text { the vulnerability of said groups (includes a variety of actors, such } \\
\text { as states and local communities). }\end{array}$ \\
\hline
\end{tabular}


Table 6 Classification of articles in to four selected categories for the climate adaptation literature

\begin{tabular}{ll}
\hline Category & Description \\
\hline $\begin{array}{l}\text { Land use/group studied } \\
\text { Vulnerability relating to climate change }\end{array}$ & $\begin{array}{l}\text { Groups studies, such as farming or pastoral communities. } \\
\text { Understanding how such communities and their livelihoods } \\
\text { are vulnerable to and affected by the negative effects of } \\
\text { climate change. }\end{array}$ \\
$\begin{array}{l}\text { Vulnerability relating to other factors (excluding climate change) } \\
\text { Thultiple variables other than climate change that contribute } \\
\text { to the vulnerability of such communities. }\end{array}$ & $\begin{array}{l}\text { Policy and other recommendations. } \\
\text { Futation recommendations }\end{array}$
\end{tabular}

communal conflicts/violence said to involve pastoral and crop-based communities as well as ethnically, religiously or otherwise marginalised communities. This SLR departs somewhat from the approach outlined by Raleigh and Kniveton [42], and goes further as set out in Fig. 1, it identifies several conflict types with corresponding groups. These conflicts involve agricultural communities, both crop farmers and pastoralists, urban populations and ethnically, religiously or other based violent conflicts. Also identified is civil war, usually involving the state against non-state actors [54] (see Fig. 1).

It is worth further noting the difficulty in documenting these conflict types and groups. The agricultural sector (includes crop based and pastoral communities) is mentioned in most studies as being the most vulnerable to the effects of climate change due to its reliance on natural precipitation patterns $[22,27,54]$. However, it is not always clear if the assertion is that it is such groups who will be involved in the conflict. For example, Burke et al.
[13]; Couttenier and Soubeyran [15] refer to civil war, yet both mention the high vulnerability of agricultural communities. Both papers use conflict data that is a part of the ongoing UCDP/PRIO ${ }^{4}$ project on armed conflict [54]. Thus, it is not clear whether agricultural communities or various other state and not state actors are the primary actors involved in, or the causes of, conflict. It could be that the vulnerability of the agricultural sector acts as a proxy for violent conflict rather than being involved in violent conflict. For example, Burke et al. [13] assert that agricultural performance is the key mechanism linking increasing temperatures to civil war in Africa (a simple causal link is contested, this will be discussed in the Summary of Results and Discussion section). The study by Rowhani et al. [44] was classified as communal violence (ill-defined) in Fig. 1. Here, the authors documented various conflicting communities in Ethiopia, Sudan and Somalia, making reference to various pre-existing ethnic, religious and other tensions, as well

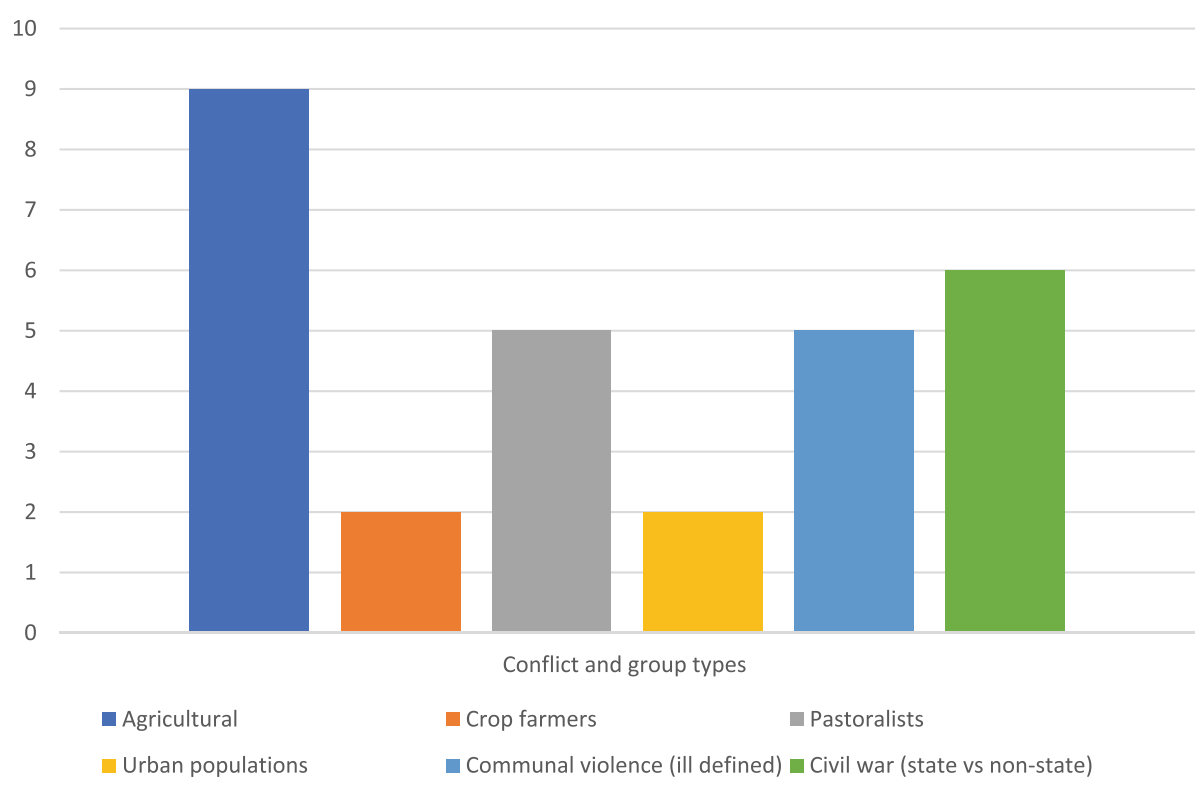

Fig. 1 Conflict types and corresponding groups 
as paying mention to large pastoral communities in the region. Here ambiguity is created as the UCDP/PRIO database was used for their conflict data as a study of civil war as encompassing: "interstate, extrastate, internal and internationalized internal armed conflict with at least 25 battle deaths between two or more parties where at least one is the government of state" [44].

Jones, Mattiacci and Braumoeller [27] further illustrate how food production and possible food insecurity (agricultural production being an important factor in food security) can affect violent unrest where vulnerability of the state is low, namely, state vulnerability moderates the effect of food insecurity and thus the likelihood of violence. This presents a clearer understanding of the groups involved in conflict and how the agricultural sector is related through its link to food security and state vulnerability. Likewise, clearly identifying pastoral communities as the key actors in conflict, allowed Adano et al. [3], Schilling et al. [47] and Theisen [53] to better identify how warming and drought impacted those communities and interacted with existing conditional and mediating factors. This being a notable benefit of the single case quantitative studies. The ambiguity in clearly defining groups involved in conflict, illustrated above, leads to a corresponding ambiguity in the defining of groups for Fig. 1, suggesting that this may be a limitation of the SLR analysis. However, the analysis would not have been able to gain the insights it did without using this approach.

\section{Vulnerability relating to climate change}

The concept of 'vulnerability' ('vulnerable' included) is explored or at least mentioned in at least $70 \%$ of the climate-conflict studies identified in this SLR, suggesting that it is a significant aspect in understanding the causal links between climate change and violent conflict. In this section, vulnerability is understood in both specific and broad terms. Broadly, vulnerability can be understood as the extent to which communities throughout Africa are impacted by the effects of climate change, due to their over reliance on rainfed agriculture [22, 27]. Thiesen, Holterman and Buhaug [54] affirm this by asserting that only $4 \%$ (2011 at time of publication) of arable land is irrigated, making agricultural communities unsuited to withstanding the effects of drought. In this context of vulnerability relating to climate change, vulnerability could be seen as the level of physical exposure to the direct effects that climatic changes pose to such communities through their high exposure and low levels of resilience [18].

For pastoral communities, physical exposure is particularly relevant as the pastoral livelihood relies predominantly on natural resources, water and pasture, which are made increasingly scarce by drought, rainfall variability and other environmental indicators [31]. Indeed, Meier, Bond and Bond [31] contend that vulnerability caused by environmental stress has changed the relationship of cooperation and competition among pastoral groups, where one of the functions of cattle raiding and theft is to replenish herds killed off during drought [14]. Raleigh and Kniveton [42] outline one of the possible climate-conflict pathways, referring to it as 'scarcity' where increased rates of conflict are likely to follow periods of higher than average decreases in rainfall. Here, a picture is developed where conflict is causally related to climate induced resource scarcity. However, contention exists where the traditional view of resource scarcity contributing to conflict is countered by the finding of Butler and Gates [14], who also present evidence supporting the narrative of an abundance in resources: water, pasture, thicker vegetation, in increasing instances of pastoral conflict. Some supporting evidence was also found for this by [31]. In the literature identified for this SLR, rainfall variability and warming were the climatic variables assessed most, both in $60 \%$ of studies. Drought was assessed $40 \%$ of studies.

Yet, Fjelde and von Uexkull [18] contend that vulnerability is not only determined by the level of physical exposure, but by the level of resilience in communities or states, which depends on the ability of societies to respond and manage the effects of climate change. Ide et al. [25] confirm this notion of 'exposure', describing it as the adverse impact of a particular climatic variable such as drought or warming. The authors expand on this, pointing to 'sensitivity', which is similar, but refers to the degree to which a system or community is affected by such climatic changes [25].

Here, it is worth noting how an understanding of vulnerability in the context of exposure and sensitivity is not always reached using these explicit terms in many papers. More often, rather than authors referring to or assessing exposure and sensitivity explicitly, the impact of the climatic changes will be addressed, such as drought or reduced rainfall. For example (some already described above) Thiesen, Holterman and Buhaug [54], outline the impact of increasing instances of drought on rainfed reliant agricultural communities in some of the poorest and most vulnerable parts of Africa. Drought and measurements of precipitation are the climatic variables used by the authors, they are illustrated without referring to exposure and sensitivity in such definitive terms. Yet, as illustrated by Ide et al. [25], exploring these changes more explicitly in the terms of exposure and sensitivity, can allow the authors to better visualise how these climatic changes affect a given community, and indeed how they may be a part of a climate-conflict causal link. This points to a gap in the research. 
What will be made clear in the next section is that the climate effect on vulnerability is only a contributing factor, where the term 'adaptive capacity' could be seen as the ability of a community to manage adverse climate impacts. This 'capacity' refers to the importance of the multiple factors identified that describe how communities are vulnerable [17].

\section{Vulnerability relating to other factors}

What is clear in the literature is that there are multiple variables that contribute to the extent that communities become vulnerable to the negative impacts of climate change. Ide et al. [25], as the third aspect of vulnerability the authors refer to, outline 'adaptive capacity' which is the ability of a system or community to change in order that it can cope with and manage the stress it faces due to its exposure and sensitivity. Rowhani et al. [44] find evidence for the importance of interannual rainfall variability on affecting ecosystem production (strength of the natural ecosystem/natural resources). As malnutrition is statistically associated with violent conflict, ecosystem production and rainfall variability are indirectly associated with violent conflict. What is indicated here is that this potential climate-conflict link is mediated by what can reduce malnutrition. Accessibility to health services for example, through robust infrastructure, can decrease the impact of malnutrition. Strong economic institutions and robust economic growth can also reduce the vulnerability of those who experience malnutrition and rely on ecosystem productivity [44].

In their analysis, Devitt and Tol [17] develop a model of development with multiple interactions. They find that climate change increases the probability of civil war, yet economic growth reduces this likelihood as well as vulnerability to climate change, where climate change and civil war both act as poverty traps and can reinforce one another. Here there is a simplified implication, if economic growth is strong, countries will experience greater wealth and peace, and be able to withstand the effects of climate change [17]. However, not all African states and agricultural (or otherwise) communities will experience the same level of underdevelopment, lack of access, or economic growth and thus vulnerability. Indeed, Thiesen, Holterman and Buhaug [54] confirm this through asserting that differing groups in such societies are not all equally vulnerable to environmental shocks, paying mention to politically and ethnically marginalized groups. A feature of their study, for example, was to geographically disaggregate their research design, selecting for groups experiencing such marginalization, implying that climate related conflicts are more likely to occur in these regions. Raleigh, Choi and Kniveton [41] echo this important realization of where communities are most vulnerable. They outline how conflict rates are in some cases subject to already degraded environments, for example where communities are already experiencing higher conflict rates, ultimately stating that the scale at which phenomena are addressed and studied, as noted above, is of great importance. Further, Raleigh, Choi and Kniveton [41] include food prices and market strength for their model, as important mediating factors for, and between, vulnerability, climate and conflict.

In their study, Fjelde and von Uexkull argue that studying communities at the local level is important in discovering how they experience and respond differently not only to physical, but also to political and economic vulnerability. Capturing these local details provides an advantage relative to those studies which are designed at the state level [18]. The authors look specifically at income and poverty of local communities as their economic variable. However, they also account for specific livelihood requirements and reliance on agriculture, rather than just a measure of poverty. This, in concert with political marginalization, can push groups to violent pathways in voicing frustration when peaceful alternatives are not present [18]. Here, an understanding is developed of how variables other than those which are climatic and centred on the specifics of exposure and sensitivity, are of great importance in determining vulnerability. For example, Ide et al. [25] contend some regions and communities might experience higher sensitivity to climatic changes if they consist of poor, highly populous regions that are highly dependent on rainfed agriculture. Thus, Ide et al. [25], using indicators for exposure, sensitivity and adaptive capacity, were able to generate a composite risk index (CRI). Variables for exposure were temperature and rainfall variability. For sensitivity and adaptive capacity, the authors identified measures including communal and household vulnerability, governance vulnerability and population density, environmental dependence and soil degradation. Ide et al. [25] point out however, that such areas which are highly exposed, sensitive and have a low adaptive capacity, will not necessarily experience violent conflict. Thus, there is also a third consideration in developing their CRI, namely a general risk of violent conflict, which is defined as the likelihood of violent conflict to break out in a certain area $^{5}$. Possible indicators include low economic growth, lower levels of democratization, recent conflicts and low levels of development among others [25]. Through this process the authors could develop 
a most likely scenario for when and where future violent conflict might occur. The study argued that if there is a link between climate change and violent conflict, it is most likely to occur in areas that simultaneously experience high exposure to climate change, a high vulnerability (high sensitivity and low adaptive capacity) to climate change and a high general risk of violent conflict onset [25].

In contrast to this detailed exploration at the subnational level, Jones, Mattiacci and Braumoeller [27] chose to analyse vulnerability at the national level. The authors sought to model the relationship between climate change and violent unrest by accounting for the complex relationship between food insecurity and state vulnerability. Threats to food insecurity is a complex phenomenon and is accounted for through two central processes: extreme environmental change and international food prices. Jones, Mattiacci and Braumoeller [27] contend that threats of food insecurity to the occurrence of violent unrest is moderated by the level of state vulnerability. Here, state vulnerability is a multi-dimensional concept determined by two key features: the states' susceptibility to food insecurity and the states' capacity to manage and mitigate rapid changes in the face of threats to food insecurity [27]. Through this view, it was demonstrated that state vulnerability plays an important role in shaping the relationship between food insecurity and violent conflict. Reducing the vulnerability of that state can address the two key ways in which food insecurity can contribute to violent protests and riots identified in their study: food shortages and food entitlements (food entitlements entails the relative control of segments of the population over food distribution) [27]. It is worth noting that there is much overlap between the non-climatic variables that are seen to make a community (or state) vulnerable (as explored above) and the non-climatic variables that are argued to cause or contribute to violent conflict. Vulnerability in this context, referred to as adaptive capacity by Ide et al. [25], is not always referred to as such (less than 15\% of studies do so in the climate-conflict literature) illustrating a gap in the literature. Rather, authors often refer to the variables studied themselves. For example, Raleigh and Kniveton [42] assert that the climate effect on conflict is mediated by political and economic variables, whilst Jones, Mattiacci and Braumoeller [27], point to state vulnerability and the strength of state institutions (economic and political) which mediate the threat posed by climate induced food insecurity. It may just be a choice between how authors choose to define their selected variables. However, as shown above, authors who frame vulnerability and mediating factors in the climate-conflict context by illustrating adaptive capacity, gain a clearer understanding as to the potential conflict risk and causal pathways [25, 27].

\section{Peacebuilding and conflict prevention recommendations}

This SLR confirms the already reached consensus that any causal links in the climate-conflict debate are likely to be indirect, mediated by a host of other socio-political, economic and other factors. Therefore, outlining definitive initiatives for policy makers to counter any causal links could result in ill-conceived policy recommendations as the evidence base itself is not yet

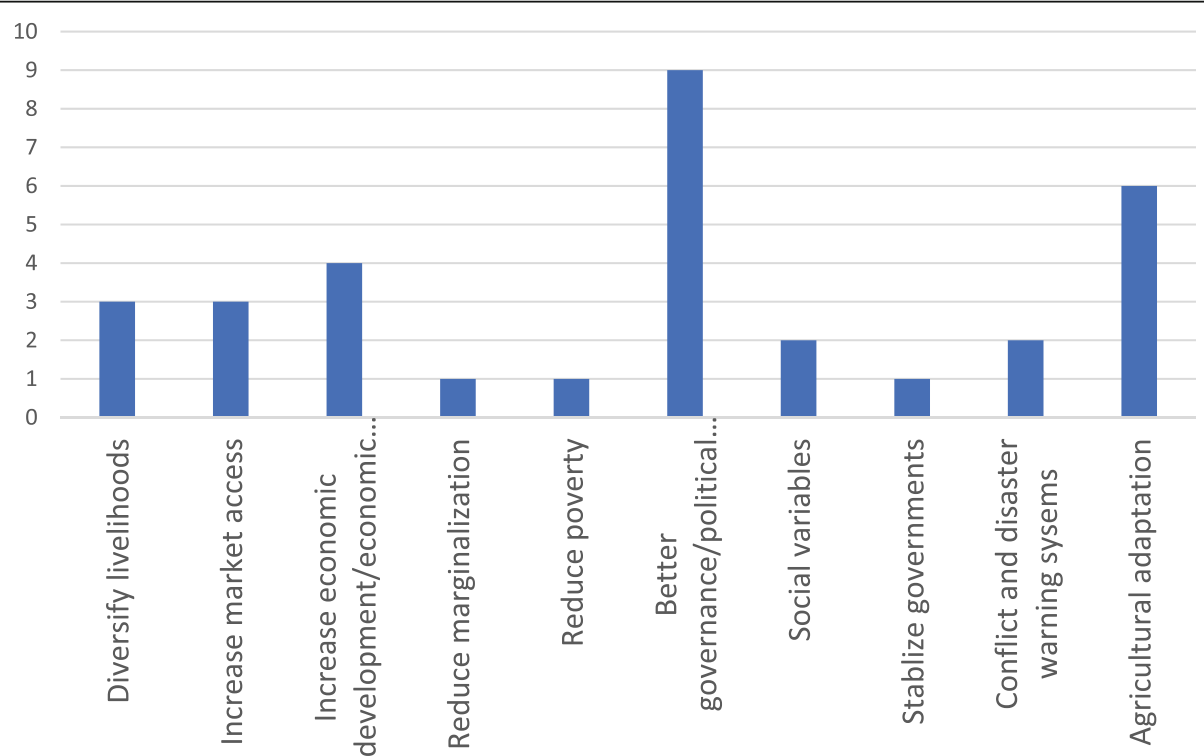

Fig. 2 Peacebuilding and conflict prevention strategies mentioned 
conclusive. However, just over half, $51 \%$, of the studies identified in this SLR still make carefully qualified peacebuilding and conflict prevention recommendations based on their individual analyses as outlined in Fig. 2.

The most commonly sited conflict prevention recommendation, as seen in Fig. 2, was 'Better governance/political variables'. This also confirms the consensus that variables other than climate change contribute to violent conflict. Some of the studies make general references to the inclusion of political or governance related efforts, for example Meier, Bond and Bond [31] assert that broad political variables need to be taken into consideration as possible response mechanisms. Hendrix and Salehyan [23] call for the promotion of transparent government institutions in order that citizens can have their demands met through regular and peaceful means. Looking at the prevalence of politically marginalized communities in arid and semi-arid lands (ASAL), Raleigh and Kniveton [42] assert the need for greater management of communal conflict. In a similar context, Witmer et al. [60] call for an increase in good governance, specifically, political rights and political freedom, to better prevent conflict. On the other hand, concerning the role of the market in mitigating conflict risk, Raleigh, Choi and Kniveton [41] outline the importance for better governance and management in the volatility of food prices, to increase market development and to ensure market assistance in times of need.

A number of broad economic development/variables are mentioned for their utility in mitigating conflict risk $[10,31]$. Burke et al. [13] identify the specific need for insurance schemes to help protect the poor from the negative impacts of adverse climatic shocks on their crops. Burke et al. [13] also identify the need for foreign aid to be contingent on the event of climatic risks or disasters to strengthen a communities' economic resilience.

A range of other recommendations are made from climate and disaster warning systems [31], to increasing market access for remote communities [23] and to stabilizing democratic governments [36]. Three of the studies also mention the importance of ensuring the adaptation of the agricultural sector to enhance resilience to adverse climate impacts. Burke et al. [13] assert the need to ensure African crops are resilient to increasing extreme temperatures through expanding farmer knowledge, increasing irrigation and expanding crop diversity and genetic enhancements [10]. Hendrix and Salehyan [23] also mention the need for irrigation and increased variety of seeds as well improving water storage. This underscores the assertion that adaptation should be a part of future conflict prevention strategies. Yet, the fact that there is sparse analysis and even mention of adaptation in the literature indicates a gap in the research.

\section{Climate adaptation results Group/land use type studied}

For the selected literature, agriculture was the observed land use in all papers. For this study, agriculture was seen to encompass both crop based farming as well as livestock husbandry, with variations including 'crop based' (not specified for single or mixed crop), 'single crop,' 'mixed crop,' 'mixed use' (referring to crop and livestock based farms), 'crop and livestock' (for studies that looked at crop and livestock based livelihoods separately), 'livestock' and 'not stated' as seen in Fig. 3.

The literature covers some broad categories concerning climate adaption, including measuring adaptation options and constraints, determinants of past and

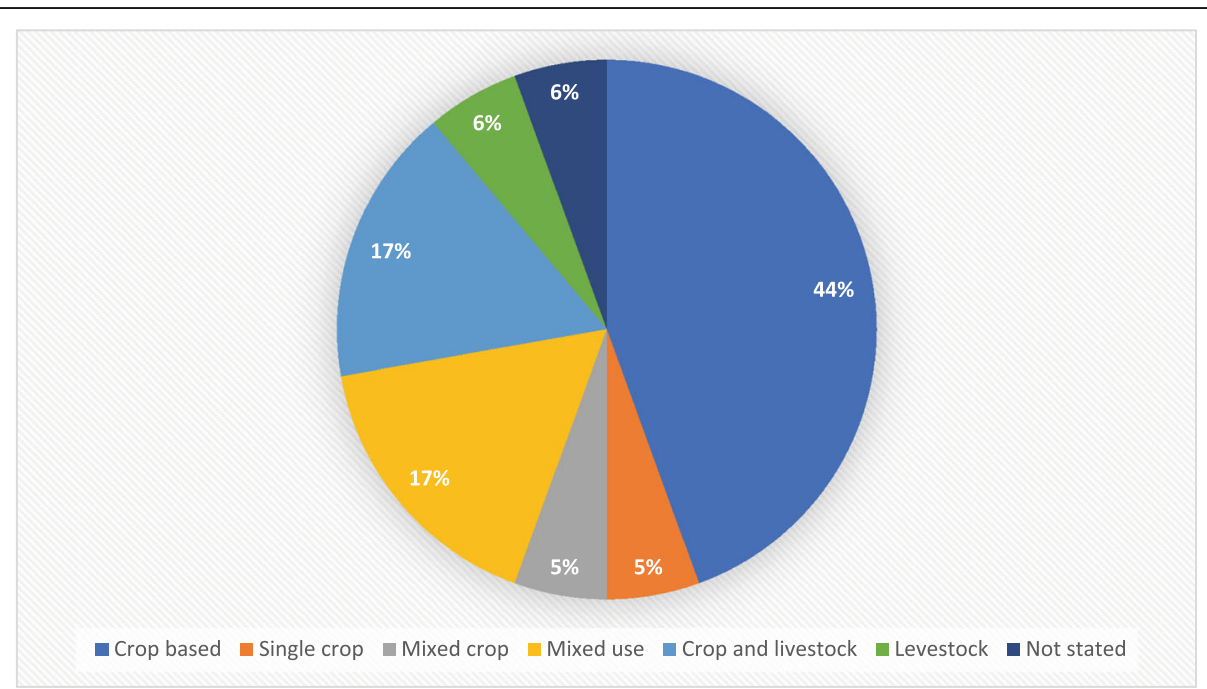

Fig. 3 Identified agricultural land use variations 
current adaptation strategies, and farmer perceptions to climate change and adaptation. Farmer perceptions of the threats posed by climate change were measured by $42 \%$ of the papers. Among those, there was generally a considerable level of awareness as to how the climate was changing and would continue to do so. In their study of 8000 farm households across eleven countries, Hassan and Nhemachena [20] showed that $50 \%$ of the farmers perceived long term changes in the climate, notably in warming and precipitation changes. Bryan et al. [7] illustrated that in South Africa, 86 and $79 \%$ of farmers noted that temperatures had increased, and rainfall dropped respectively. For Ethiopia, such awareness was 65 and $64 \%$ for increasing temperatures and decreasing rainfall respectively. Analysing affected groups at such a specified level, as farmer households and communities, allows for granular data collection. Importantly, as is evident, this allows researchers and policy makers to better asses the specific adaptation needs of agricultural communities and how adaptation strategies can be enhanced for the future.

\section{Vulnerability relating to climate change}

The value of adaptation for any local community or state actor is assumed and has been clearly enunciated in IPCC reports for nearly 30 years, including the most recent one [26]. It is, however, beyond the scope of this particular SLR to provide a thorough analysis as to the scholarly debate regarding the specifics of climate adaptation methods used. There is a broad consensus in the literature that adaptation is needed to cope with current and future changes in the climate. Successful adaptation in the agricultural sector is needed to meet future demands on food production ${ }^{6}$ and help vulnerable communities cope with changes to their livelihoods [7, 19].

In the climate adaptation literature, vulnerability is mentioned and addressed in $68 \%$ of the studies, indicating its importance to understanding community needs for climate adaptation. Rather than assessing vulnerability in the context of understanding the potential for a climate conflict link, it is understood in the context of climate adaptation needs and constraints. Hassan and Nhemachena [20] assert that vulnerability to climate change is high in many African communities as their adaptive capacities are low. This is largely because climate change is expected to adversely affect food and water resources that are essential to the livelihoods of such communities. Here, adaptation can help achieve the livelihood goals of farming communities in the face of vulnerability to climatic changes [20]. Bryan et al. [7] confirm this assertion, stating that adaptation measures taken by rural agricultural communities can help them manage and adjust to the negative effects of climate change, thereby reducing their level of vulnerability to environmental changes. Relating to the direct effects of climatic changes, vulnerability is better understood as crop and livestock susceptibility to climatic changes [59]. In analysing the vulnerability of the West African Cocoa belt, Schroth et al. [49] point out how past increased warming and drought periods have severely reduced cocoa production, and fears of future projected temperature increases, and rainfall variability are renewing these concerns. Overall climate suitability for cocoa in West Africa is projected to decrease, with low and intermediate zones of climate suitability decreasing throughout the cocoa belt. This will present a challenging future for many agricultural communities in the region, where $70 \%$ of the world's cocoa is produced [49].

Agricultural communities that incorporate or focus on livestock exclusively experience such vulnerabilities too, where livestock are susceptible to increases in disease outbreak, weight loss and reductions to their natural environments and food sources [50]. Oyekale [38] for example, primarily assesses the impact of climate change on livestock among farming communities in the Sahel region, noting livestock husbandry is extremely vulnerable to drought. The author concluded that goat, sheep and oxen were the most at threat, often from pests and diseases. Here the author noted that such animals are often used as a form of wealth storage. By being sold off during times of drought, the animals will often act as a buffer to minimize harmful effects of drought [38].

From the above, vulnerability is understood in a comparatively similar sense to the understanding presented in the previous section on the climate-conflict nexus vulnerability as physical exposure. In Schroth et al's. ([49], 232) analysis of cocoa in West Africa, the authors describe vulnerability to climate change as the "combination of exposure (the nature and extent of climate change) and sensitivity (the impact of this change on local systems, here cocoa)". Schilling et al. [48] confirm these aspects of exposure and sensitivity. For their analysis, the authors assess sensitivity in the context of natural resource availability and the importance of these resources in North African states. Schilling et al. [48] assess water availability as perhaps the key natural resource that the agricultural sector is most sensitive to. All North African countries used in their analysis are either termed as water stressed or scarce. This is a notable issue when it is taken into account that $90 \%$ of Moroccan land for example (2012 at the time of publication), rely on rainfed water sources, with precipitation likely to generally decrease with temperatures increasing. For the studies identified in this SLR for climate adaptation, rainfall variability was assessed in $68 \%$ of the studies. Warming and drought was looked at in 63 and $31 \%$ of the studies respectively. 
A focus on exposure and sensitivity with regards to vulnerability and needs for adaptation, alludes to the position that farmers need only direct their adaptation efforts where climate change and variability is concerned. For example, developing drought resistant crop varieties, or introducing multiple crops to reduce the increased vulnerability experienced through mono cropping [59]. However, it is important to understand how these farming communities become vulnerable, thereby affecting their capacity to adapt. Schilling et al. [48], through illustrating a third component of vulnerability, adaptive capacity, refer to 'generic adaptive capacity' which concerns the general factors and indicators such as economic development, education and healthcare. Schilling et al. [48] also illustrate 'specific adaptive capacity', which are those indicators specific to an impact, which might include institutional performance, knowledge and technological development.

Understanding the complex and numerous factors that undermine a community's capacity or institution's capacity to adapt, is key to understanding the vulnerability of such communities to climatic changes. It goes beyond an understanding of how these communities are affected by these changes (exposure and sensitivity). The following section will further explore this complex relationship.

\section{Vulnerability relating to other factors}

Whilst the previous section addressed vulnerability reduction through various methods of farm level adaptation, crop diversification and mixed-use farming among others, as direct actions to manage the impacts of climate change, what follows will address general and specific indirect factors that increase vulnerability to climate change. Hassan and Nhemachena [20] assert that vulnerable African farmers need support from public policy initiatives and investment to enhance their capacity to adapt to climate change. In assessing adaptation of cocoa to climate change, Schroth et al. [49] outline the necessity for government policies to guide and encourage adaptation measures such as the intensification of cocoa farms. Bryan et al. [7] illustrate the need for government intervention to assist with guiding the adaptation process, particularly in balancing what the authors refer to as 'strategic adaptation' of the agricultural system. This involves balancing the benefits of coping with short term climate effects and adapting to long terms ones to best manage impacts and ensure that no harm in the process is created. This points to accounting for pre-existing vulnerabilities, potentially those that are structural within a community [21]. Ozor, Urama and Mwangi [56] outline the presence of multiple stressors which significantly enhance climate related vulnerability, and which have constrained community development, such as poor governance, poverty, lack of market access and low technological development. Clearly there are many factors which influence the agricultural system, either helping or hindering the process. It is important then to consider the scale of analysis for adaptation whether that be at the level of the farm, local government, state or international institutions [7]. Those identified in this SLR consist of the local community or the farm level as outlined earlier. With the aim of improving adaptive capacity at the household and farm level, Nhemachena, Hassan and Chakwizira [34] point to the need for government policies to support research and development that supply farmers with the appropriate technology, the enhancement of crop development, provision of climate information as well as financially supporting specific adaptation measures such as irrigation.

In measuring farmer perceptions to climate change, Mertz et al. [32] contend that climate related factors, notably precipitation and temperature changes, play a limited role $(30 \%)$ in determining adaptation, relative to other factors. This leads the authors to assert that focusing adaptation strategies to reduce vulnerability exclusively on climatic variables, would not be sufficient [32] Urama and Ozor [56] point to a lack of income, lack of government support and absence of reliable institutions to assist in providing the necessary capacity to adapt.

Referring to adaptive capacity as outlined earlier, Schilling et al. [48] point to several general indicators in identifying Morocco as the most vulnerable in their analysis of North Africa. The authors state that in looking at economic wealth and resources it is important to consider distribution as opposed to per capita income only. $\mathrm{Hu}-$ man development, health and education are the remaining indicators used in identifying Morocco with the lowest adaptive capacity [48]. In identifying specific indicators of adaptive capacity, the authors refer to institutional performance, of which the level of corruption is a key indicator, as well as the availability of knowledge and new technologies [34, 48]. A combination of high exposure to climate change, high sensitivity and low adaptive capacity is argued to constitute a highly vulnerable community to the effects of climate change [48]. Nhemachena, Hassan and Chakwizira [34] refer to evidence from their analysis of farmers from South Africa, Zambia and Zimbabwe as to their perceptions of adaptation determinants, lending credence to the importance of 'specific' adaptive capacity. Their research looks at responses of farmers, highlighting the need for increased credit, access to information (both climate and agronomic) and increased market access, to increase their adaptive capacity $[28,34]$. As noted in the climate-conflict section previously, it is important to note again that vulnerability relating to factors other 
than climate change (adaptive capacity) should not been seen as necessarily separate from what are identified to be barriers to implementing adaptation strategies. Indeed, barriers to adaptation are what can cause or contribute to a system having a low adaptive capacity. For example, political and geographical marginalization is a barrier to farming communities attaining the government assistance they need [34]. It may be the case that some authors choose to (or choose not to) frame their analysis in the context of analysing barriers to adaptation and vulnerability specifically through the frame of adaptive capacity. As stated before, authors such as Schilling et al. [48] who do this, could attain a better or at least a more detailed understanding of how communities become vulnerable and what their future adaptation needs are.

Considering the above, it is of clear value to take into account the broader spectrum of variables that constitute a thorough understanding of 'vulnerability' and what constitutes its occurrence. Recognizing the importance of how communities are endowed with, or develop, a low adaptive capacity [48], illustrates the need for comprehensive adaptation needs that account for this complex interaction of variables, rather than focusing on adaptation responding only to climatic variables [32].

\section{Recommendations to enhance adaptation}

Of the papers identified in this SLR, 79\% offer suggestions and policy recommendations for future adaptation initiatives. Recommendations are represented as total number of mentions in Fig. 4.
Figure 4 represents the major adaptation strategies recommended in the literature. According to the data collected in this SLR, 33\% of adaptation recommendations are focused on farm level adaptation which centres on the physical or the 'exposure' and 'sensitivity' aspects of vulnerability. However, most recommendations, 67\%, centre on the 'adaptive capacity' aspect of determining vulnerability to climate change. In other words, such suggested adaptation strategies centre on factors which describe how a community becomes vulnerable through reducing their capacity to adapt to climate change. This lends support to the previous section in understanding the importance of how this complex interaction of factors, other than climate change, determine to what extent a community is able to adapt to the adverse impacts of climate change. Similarly, this correlates well with what was illustrated in the climate-conflict literature, where it is paramount to consider variables other than climatic indicators that influence an increased conflict risk. This link between the two bodies of literature will be further explored later in the analysis.

\section{Summary of results and discussion}

The purpose of this SLR was to review the literature on climate change and violent conflict (climate-conflict nexus) and climate change adaptation (climate adaptation) to uncover links between the two fields. Specifically, the aim was to discover how such links might inform future research and policy on how climate adaptation can contribute to the prevention of violent conflict.

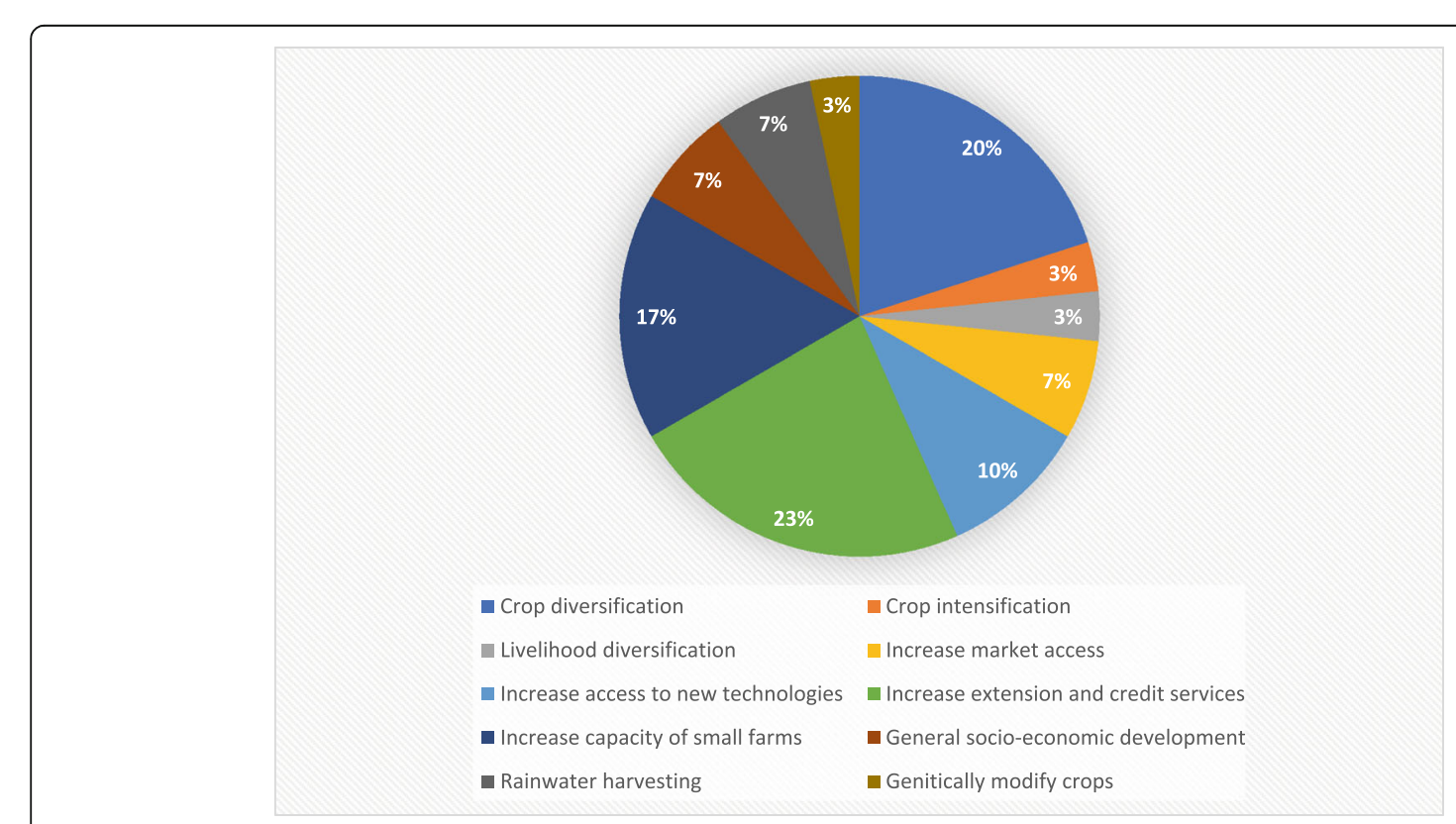

Fig. 4 Recommendations for future adaptation measures 
This SLR has revealed that there are prominent links between the climate-conflict field of research and the field of climate adaptation, and these links do inform how further research should be conducted into the notion of climate adaptation as conflict prevention. This section will summarize and discuss in depth the relevant gaps in the literature as well as what is known and how the key research aims are informed.

\section{Summary of key findings and key research gaps Group/land use types}

With regards to group/land-use types studied, the climate-conflict nexus has notable difficulties with respect to classifying those explicitly involved in violent conflict or those who are seen to be part of the causal links. Earlier quantitative comparative studies often focused on civil war and civil conflict, making state actors or large rebel groups the key actors involved in conflict $[13,17,22]$. Here, the agricultural sector would often be seen to be playing a mediating role in conflict as many African economies had large contributions from the agricultural sector, which are mostly subject to natural climatic cycles. However, as identified earlier there is a lack of clear and consistent identification of group types involved in conflict as well as how the agricultural sector and communities are a part of the causal links, thereby indicating a gap in the research. This conclusion is supported by the fact that in contrast to the climate-conflict studies, the land-use and groups studied in the climate adaptation literature are all clearly defined within the agricultural sector, with 'crop based' farms being the most studied at $44 \%$ of studies (refer to Fig. 3 for details). This clarity enabled the researchers to clearly identify adaptation needs appropriate to a given context. Importantly for this SLR, it enabled researchers to identify with greater certainty how identified groups are vulnerable, what constitutes their vulnerability and how their adaptive capacity can be increased. As has been demonstrated in both fields of literature and particularly in climate adaptation studies, increasing the adaptive capacity of an identified agricultural community reduces the impact of climatic and environmental changes. This process clarifies the link between the two fields of literature and makes evident the potential for adaptation to reduce conflict risk of an identified agricultural community.

Considering the above and to clarify the finding for this section, future research into climate adaptation as conflict prevention should make use of sub-national disaggregated data whilst outlining a specific group/land-use type. Doing so will assist in outlining where and what groups will experience increased conflict risk and therefore how adaptation might reduce this risk for violent conflict.

\section{Understanding vulnerability as it relates to climate change}

For this paper, vulnerability was separated into two broad understandings, vulnerability relating to climate change and to other variables. In both fields of research, climate-conflict and climate adaptation, vulnerability as relating to climate change was understood as how the studied groups are physically vulnerable to the negative impacts of climate change. Fjelde and von Uexkull [58] interpreted this as physical exposure, meaning how a community is affected by climatic changes such as drought or rainfall variability. Ide et al. [25] extend this understanding by also referring to sensitivity, which includes the degree to which a community is likely to be affected by such changes.

While vulnerability is mentioned in most papers in both fields of research, exposure and sensitivity (as aspects of vulnerability) are only explicitly explored in 5\% and less than $20 \%$ of studies in the climate-conflict and climate adaptation literature respectively. Rather, in both the climate-conflict and climate adaptation literature, these aspects of vulnerability are often explored in terms of the climatic changes themselves (ie drought, warming), without necessarily referring to these changes in the context of sensitivity and exposure. This indicates that these aspects of vulnerability can also be referred to as those climatic changes that are theorized to be a part of a climate-conflict link and in the climate adaptation literature, the climatic threats to crop production for example. Yet, due to the importance of illustrating vulnerability through exposure and sensitivity, rather than just physical impacts, the small number of studies that do so illustrates a gap in the literature.

With respect to the climate-conflict literature, vulnerability is often characterised by the dependence of local agricultural communities on the natural resources in their environment. This is where disruptions to the reliance of agricultural communities on their local environment are changed, either through increasing the scarcity or the abundance of natural resources, and how this can lead to an increased risk of violent conflict [14, 22, 27, 31]. And in the climate adaptation literature, this understanding of exposure and sensitivity assisted Schroth et al. [49] to identify specific vulnerabilities, barriers to adaptation and importantly, appropriate adaptation measures that focused on reducing the negative climate impacts on cocoa in the West Africa region. Identifying physical vulnerability through exposure and sensitivity can enhance our understanding of how climatic impacts can be reduced for an identified agricultural community, vulnerability becomes a clear link between the fields of research. Identifying the exposure and sensitivity of a community/group type, has clear benefit in the climate adaptation literature in illustrating how the physical 
vulnerability can be reduced, and hence how conflict risk can be reduced.

The concept of vulnerability was thus the key link uncovered in this SLR between the two fields of research. Understanding this concept can inform future research on climate adaptation as conflict prevention. Thus, the paper develops this insight further and later posits the importance of a Vulnerability Model.

\section{Understanding vulnerability as it relates to other factors}

Understanding the third aspect of vulnerability, namely adaptive capacity, accounts for the multiple variables that increase the risk for climate related violent conflict and those factors which reduce the capacity for agricultural communities to adapt to climate change.

Most authors do not stress the importance of adaptive capacity as an indicator of vulnerability in the climate conflict literature (less than $15 \%$ do so). In the climate adaptation literature, it is done more frequently $(60 \%$ of studies). However, only one study in each field used the elements of exposure, sensitivity and adaptive capacity (it is beyond thescope of this SLR to evaluate this impact on the climate adaptation literature, as this paper is focused on the climate-conflict debate and conflict prevention). The variables that are assessed are most often referred to as the variables themselves, for example Raleigh and Kniveton [42] assert that the effect of climate on violent conflict is mediated by various economic and political variables.

Addressing the three elements of vulnerability was best illustrated by Ide et al. [25]. Here, the author's stated intention was not for their analysis to serve as an explicit attempt to add to the quantitative comparative literature in the manner of finding a statistically significant link, but rather to serve as a risk assessment for where conflict might occur. It nonetheless adds to the debate in how to theorise a causal pathway. In the climate adaptation literature, a similar approach in outlining exposure, sensitivity and adaptive capacity was illustrated by Schilling et al. [48]. Considering that these two above mentioned analyses are the only ones to follow this outline, demonstrates a clear gap in the literature. Specifically, this presents a gap for future studies aiming to theorize how climate adaptation could prevent and reduce the risk of future violent conflict occurring.

Ide et al. [25] assert that adaptive capacity is the ability of a community to change so that it can cope with the negative impacts of climate change (referring to exposure and sensitivity). This suggests it is necessary to look for factors which decrease the capacity of a system to adapt to changes in the environment when attempting to link climatic changes to conflict as set out in Fig. 1. Ide et al. [25] also point to other localized indicators that decrease adaptive capacity, such as low access to health care and related daily necessities such as food and water consumption, as well as low levels of education. Such indicators are basic requirements for providing people in vulnerable communities (agricultural in the case of [25]) with the ability to cope and manage adverse impacts of climate change and find alternative means of living if necessary. Crucially, Ide et al. [25] also account for variables that constitute a general risk for violent conflict, as included in the CRI in modelling conflict risk at the subnational level. Thus, a focus on climatic indicators/variables (increasing temperatures for example) and their direct impact on a system (the agricultural system/communities for example) in the climate-conflict literature, can lead to the impression that there are relatively simple and direct causal links between climate change and violent conflict. However, this is clearly contested in the literature, where, if such a climate causal link exists, it is asserted to be mediated by a multiplicity of other variables [10, 11, 54]. One example in search of a climate-conflict link follows Thiesen, Holtermann and Buhaug [54], who assess rural communities experiencing political and ethnic marginalization, which are factors that increase their vulnerability to climatic changes.

Hence, as was explored in the 'Result Synthesis' section, adaptive capacity can be seen to account for these multiple variables in fully understanding the indicators of vulnerability, and how this informs what and where a climate conflict link might occur. It is therefore important to consider those factors which could be seen to constitute a general risk of violent conflict. Such factors may not overlap with those variables which are seen to mediate the impact of climatic changes as previously outlined (refer to footnote ten).

A benefit that the extant adaptation literature holds over that of the climate-conflict, is the ability to perform micro analyses of a community's vulnerability, partly due to identifying specific group types for study more often, as well as for collecting highly granular data for analysis, often at the household level. In such cases, more detail can be gained with regards to a community's sensitivity to climatic changes, as well as what constitutes/contributes to their inability to adapt to climate change, such as barriers to adopting rain water harvesting tanks, diversifying of crops and livelihoods among others $[29,49]$. This addresses, at least in part, that micro-level economic factors in general and aspects of vulnerability are not well understood in relation to increasing conflict risk [58].

In the climate adaptation literature, adaptive capacity and vulnerability are rather understood in the context of assessing, among other aspects, future needs for adaptation; thus adaptive capacity can be specifically understood as those variables that inhibit the potential for a community (refer to Fig. 3) to adapt to the negative impacts of climate change. For example, Mertz et al. [32] 
assert that, due to the more limited role that climatic factors have played in determining past adaptation measures (30\% by their analysis), it is imperative to account for alternative factors in determining adaptation needs. At the structural level, Hassan and Nhemachena [20] outline the need for public policy initiatives and investment to enhance the adaptive capacity of farmers and Scroth et al. [49] illustrate the need for government policies to support farming intensification in the West African Cocoa belt. Schilling et al. [48] more specifically refer to elements of adaptive capacity and in doing so are able to better understand adaptation needs of the agricultural sector across North Africa where they focus on Morocco. In identifying specific indicators of adaptive capacity, the authors refer to institutional performance, of which the level of corruption is a key indicator, as well as the availability of knowledge and new technologies. Schilling et al. [48] also illustrate several general indicators of adaptive capacity. The authors state the importance of looking at the distribution of economic wealth and resources, also noting human development, health and education, as indicators used to identify Morocco with the lowest adaptive capacity.

As illustrated above, there is a clear demonstrated value in recognizing how identifying elements of adaptive capacity can enhance the ability of a community to reduce the climatic impacts on agricultural and pastoral systems for example. Here a bridge in common understanding is observed between the two fields of literature.

Therefore, through accounting for the variables relating not only to exposure and sensitivity, but adaptive capacity as well, a more thorough understanding is reached as to how climate adaptation can prevent and reduce the risk for violent conflict.

\section{Implications for future quantitative comparative research}

This SLR confirms the current consensus that any causal links between a changing climate and conflict are mediated by number of socio-economic and political factors. Here we suggest that future quantitative comparative studies seeking to find such causal links would benefit by drawing variables for quantification from the previous illustrations of vulnerability, as well as with a focus on a specific group type, namely agricultural communities. This has been explored in more detail in the next section.

Studies that consider the specific aspects of vulnerability and which have attempted to outline a group type, have thus been able to narrow plausible outcomes or causal pathways to where a causal link may occur, for example $[25,27]$ or conversely, to be able to discount a climate-conflict link $[5,9,10]$. The benefit of outlining a specific group type and extant aspects of exposure, sensitivity and adaptive capacity, was also demonstrated in the climate adaptation literature. Schilling et al. [48] could assess those agricultural communities most vulnerable to climate change in North Africa (Moroccan agricultural communities), and thus the appropriate future adaptation initiatives that would affect growth in their resilience to the negative impacts of climate change. In addition, by using fine grained data often at the household level, studies in the adaptation literature were also able to better understand factors at the micro level which influence an identified community's propensity for conflict as well as their ability to adapt to climate change, a need expressed by von Uexkull [58]. Thus, as a reiteration, it is suggested here that future quantitative comparative research in the climate-conflict nexus should clearly outline the group type/community studied, whilst simultaneously identifying the factors and variables which constitute a group's vulnerability to climate change specifically through identifying aspects of exposure, sensitivity and adaptive capacity.

\section{Peacebuilding and climate adaptation recommendations}

In referring to Appendix (column six, policy recommendations), it is worth briefly summarizing the significance of the shared policy recommendations between both fields of research, for the key aims of this SLR, and the conflict prevention potential existing in the adaptation policy recommendations. In the climate-conflict literature the peacebuilding recommendation mentioned the most was 'better governance/political variables', with broad political variables having the potential to reduce the conditions for violent conflict to develop [31]. Raleigh and Kniventon [42] point to the need for better institutional management of communal conflict in arid and semi-arid lands where political marginalization is often high. Recommendations relating to 'economic development/variables' are also seen to be significant, where some assert that broad economic and market development could mitigate conflict risk [10, 31].

There is clear overlap in policy recommendations in the climate adaptation literature and potential for conflict prevention. The importance of governing intuitions to increase market access, increase access to extension and credit services, to build resilience and increase adaptive capacity of agricultural communities $[7,56]$. In the adaptation literature, the need for increasing market access is corroborated by Schilling et al. [47], who observed the difficulties that basket weavers face in pastoral communities when trying to diversify their livelihoods in response to drought, thereby highlighting 'increasing market access' as potential conflict prevention option. There is also conflict prevention potential in a number of other adaptation policy recommendations, such as crop diversification, introducing livestock into 
crop-based communities (and vice versa), increasing farm technologies and assets, which can reduce a community's physical exposure and sensitivity as identified in the climate-conflict literature by Ide et al. [25], Fjelde and von Uexkull [18] among others.

As is evident in Appendix, there is also significance in the fact that the 'non-climatic variables' can also be seen as barriers to adaptation, as it is noted in the adaptation literature that such factors hinder the capacity for communities to adapt to a changing climate. Here there is clear overlap between the two fields of research, where factors concerning 'socio-economic' variables, 'governance', and 'economic growth' are shared. This suggests that whilst addressing the policy recommendations in the adaptation literature, as those factors which largely concern increasing the capacity for communities to adapt to climate change, conflict risk can simultaneously be reduced. And as von Uexkull [58] pointed out, this is a no regret approach as addressing such policy recommendations would reap broader economic and developmental benefits for rural and agricultural communities.

\section{A vulnerability model for future research}

This SLR has revealed that adequately understanding elements of exposure, sensitivity and adaptive capacity, can assist in finding potential causal pathways in the climate conflict debate. It also signifies what reduces the capacity of communities to adapt to climate change, thereby highlighting future adaptation needs. If indeed this significance bears out, as is noted through the discussion section in this SLR, then there is clear significance for the first key aim of this paper in identifying links between the climate-conflict and climate adaptation literature. And the suggested Vulnerability Model,

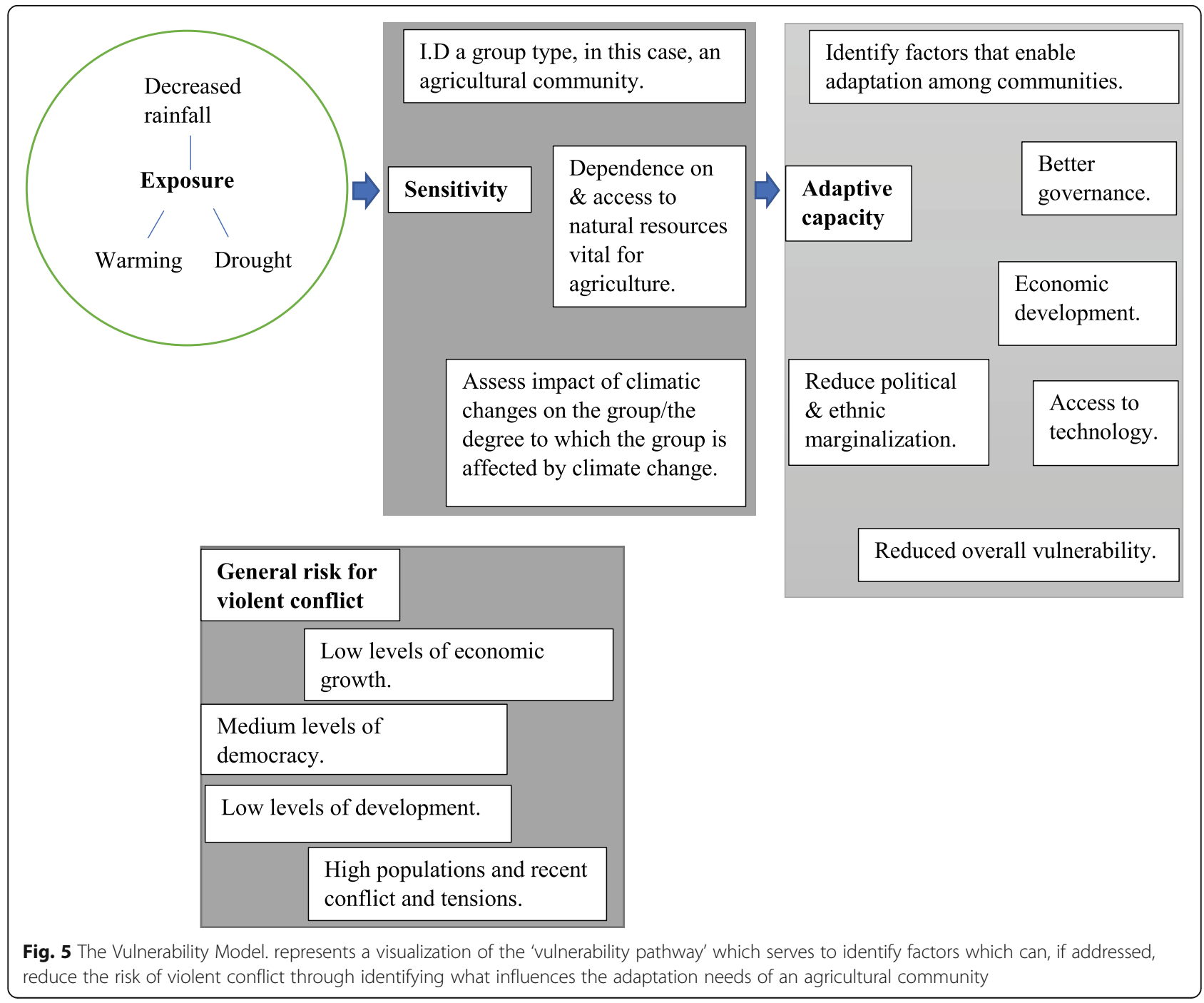


illustrates how future research can empirically quantify where future conflict risk can be reduced. Figure 5 outlines this by using the vulnerability lense of exposure, sensitivity and adaptive capacity with clearly identified actors/communities as well as indicators of a general risk for conflict. Whilst Ide et al. [25] used the framework of this model as a spatial risk assessment for future conflict we are suggesting here that future research into climate adaptation as conflict prevention should in the least aim to assess regions through this lens. We are suggesting an additional new use for this Vulnerability Model where it could be applied quantitatively to spatially assess regions for where adaptation is needed to reduce the impact of climate change as well as reduce conflict risk. The Vulnerability Model in Fig. 5 suggests how exposure, sensitivity and adaptive capacity can be measured and analysed. In so doing, a study could assess what and where a climate-conflict link might occur and what adaptation initiatives would be most suitable to prevent potential violent conflict that is seen to be related to climate change as well as fulfilling climate adaptation objectives.

Both the climate-conflict and climate adaptation literature suggest that assessing variables for exposure and sensitivity would differ little if at all. Indicators for exposure would be the climatic variable used, the commonest in both fields of research are rainfall variability, warming and drought. Taking the example of Ide et al. [25], indicators used for sensitivity and adaptive capacity, were centred around household and community vulnerability, governance/political vulnerability and population density. However, there is less certainty about the variables which reduce the adaptive capacity of agricultural communities, thereby highlighting the needs for adaptation or else there will always be an association between climate change and an increased risk of violent conflict. Therefore, those variables included in Fig. 5 for exposure, sensitivity and adaptive capacity are shared among both fields of research. In following this model for future studies, it is also suggested here to follow the example of Ide et al. [25], by including factors that are seen to constitute a general risk of violent conflict, notably low economic growth, medium level of democracy, low levels of development, recent conflict events and large populations. How these various variables are operationalized and what specific data is used is the basis of future research.

The Vulnerability Model, seen in Fig. 5, for assessing climate change vulnerability, has functional significance for empirical testing in two respects. First, that future quantitative comparative research seeking to uncover the potential for climate adaptation as conflict prevention, should begin by analysing risk factors for where violent conflict might occur that is seen to be causally related to climate change. Such future research, as demonstrated by Ide et al. [25], should progress by including variables for exposure, sensitivity and adaptive capacity, enabling researchers to understand the complexities involved, particularly those concerning the factors that mediate the impact of climatic variables. Secondly and simultaneously, this model can function to identify adaptation needs that could respond to the direct impact of climate change, thereby reducing any direct impact that climatic variables have on increasing conflict risk. And, as the evidence explored suggests, including data for the third stage would allow a study to gauge what factors increase adaptive capacity, thereby highlighting the adaptation initiatives that would best assist a community in responding to, and managing, the impacts of climate change. This duality in the Vulnerability Model was evidenced in the shared understanding of vulnerability in both fields of research. It was further evidenced earlier (with reference to Appendix), where shared policy recommendations were highlighted, and specifically how there is conflict prevention potential existing in the adaptation policy recommendations that were outlined.

A focus on the phases of exposure and sensitivity has the benefit of enabling researchers to clearly identify how climatic variables in themselves directly impact an agricultural community. Including the third phase has the benefit of clarifying how the impacts of exposure and sensitivity are mediated by factors relating to adaptive capacity, enabling a complete understanding of the influences on conflict risk and adaptation needs.

Future studies following the framework of Fig. 5 would be predictive in that the framework assists in outlining future conflict risk and potential for adaptation. The Vulnerability Model identified from this SLR (Fig. 5) is significant for future studies as it draws out the importance of vulnerability as a shared concept in both fields of literature, and importantly it highlights how future studies can empirically investigate the potential for climate adaptation in reducing future conflict risk, thereby filling existing knowledge gaps in this field.

\section{Conclusion}

This paper, based on an SLR of 46 articles centred on the climate-conflict and climate adaptation fields of research, has revealed a pattern and a key link between them that supports the aim of assessing the potential for climate adaptation to function as a pathway to conflict prevention. The systematic methodology inherent in the SLR revealed the concept of vulnerability as a key in the literature to understanding how future research into climate adaptation and conflict prevention should progress. There are three integral aspects within this vulnerability concept shared by both fields of literature: exposure, sensitivity and adaptive capacity. These were then used 
to demonstrate a Vulnerability Model that could be used for quantitative analysis leading to the prevention or reduction of conflict risk that is causally related to climate change.

The paper demonstrates the connection through vulnerability between the two fields of research, by highlighting barriers to adaptation and shared policy recommendations which often highlight variables relating to adaptive capacity, demonstrating the conflict prevention potential in such extant adaptation policy recommendations.

Though simple, this Vulnerability Model considers the various factors that mediate the impact of climatic variables on a given agricultural community and the risk for violent conflict occurring. Simultaneously, the model allows researchers to gauge what variables influence the needs to enhance the capacity of such a community to adapt to and build resilience in the face of climate change. The significance of this model lies in the potential for future researchers to better understand the variables that need to be accounted for in assessing where and when future violent conflict might occur, whilst simultaneously allowing for an assessment of appropriate adaptation options and initiatives that could contribute to the prevention of such violent conflict. This follows the example of studies that are predictive in nature, assessing the various risk factors associated with increased violent conflict risk, notably that of Ide et al. [25]. The fact that the studies presented by Ide et al. [25] and that of Schilling et al. [48] were the only two identified in this SLR as having specific relevance to developing a framework for vulnerability, presents a gap in the literature as stated in the body of this review. The Vulnerability Model specifically contributes to the filling of this gap. Thus, future researchers who are interested in the notion of how climate adaptation can contribute to conflict prevention and risk reduction, would benefit by following the framework of the Model. It is also worth noting that after reviewing the literature, and thus illustrating the evident complexity inherit in the growth of conflict, especially in a climate context, the total prevention of conflict in not likely. Thus 'climate adaptation as conflict mitigation and risk reduction' is perhaps a more appropriate view to take.

Whilst this review has focused on the conflict prevention potential in climate adaptation, it is important to be aware of the potential for adaptation efforts to aggravate existing tensions and conflicts as suggested by Bob, Bronkhorst and Sala [6].

The importance of adaptive capacity (the third important element of the Vulnerability Model) has potential policy implications aside from informing future research in this field. Policy makers and state institutions have a significant role to play in increasing the adaptive capacity of agricultural communities to adapt to climate change. These can include education and climate change awareness, increasing the economic development of rural and isolated agricultural areas in order to broaden the number of alternative livelihoods available and increasing market access. Such policies are valuable in themselves but can now be seen to also reduce violent conflict risk.

\section{Endnotes}

${ }^{1}$ The body of literature in the context of 'conflict prevention and peacebuilding' remains vast. In saying that, the use of 'conflict prevention' in this paper draws upon such literature. This literature underscores various actors that include the subnational, non-state and state actors that are active in this process. For the purpose of this paper, conflict prevention is taken to mean the prevention and mitigation of the various forms of violent conflict before its onset. This contrasts with intervening in ongoing conflicts or post-conflict peacebuilding. For the readers interest, refer to Ackerman [1] as well as UNPD [55].

${ }^{2}$ There are less than five papers identified in the climate-conflict literature in this SLR which pay mention to the potential utility of adaptation, this too will be evidenced in the body of this review.

${ }^{3}$ Providing a full sample of these data points in a table is not possible due to the amount of space required. Thus, access to the mentioned data sheets can be provided by the corresponding author upon reasonable request.

${ }^{4}$ The Uppsala Conflict Data Program (UCDP) and the Peace Research Institute Oslo (PRIO) have collaborated to produce a large dataset on armed conflict globally, from the period of 1946 to the present day. For further information, refer to the website, https://www.prio.org/ Data/Armed-Conflict/UCDP-PRIO/

${ }^{5}$ Ide et al. [25] refer to the research on the drivers' civil war onset, asserting that possible indicators for the general risk of violent conflict are best noted in this literature. This research has produced the most elaborated results and findings as to the causes for onset of violent conflict. Notable indicators include: medium level of democracy, low level of development, low economic growth, large population and recent conflicts.

${ }^{6}$ Chapter eleven of the IPCC's Fifth Assessment Report, is dedicated to agriculture, forestry and other land uses, one important reason for this dedication is that this sector is responsible for just under a quarter of the global anthropogenic greenhouse gas emissions. Interested readers would benefit from viewing this chapter (Smith et al. [52]). 


\section{Appendix}

Table 7 Final selection of articles ${ }^{a}$

\begin{tabular}{|c|c|c|c|c|c|c|}
\hline & Author & Non-climatic variables & Climatic variables & Group type/land use & Policy recommendations & Vulnerability assessed \\
\hline & \multicolumn{6}{|c|}{ Climate-conflict } \\
\hline 1 & {$[3]$.} & P, Geo & W, D & Pstrl & G (local intuitions) & No \\
\hline 2 & {$[5]$} & $M, G$ & $\mathrm{RV}, \mathrm{W}$ & CB, Pstrl & 0 & No \\
\hline 3 & {$[9]$} & EG, EPM & W, D & CW & AA & No \\
\hline 4 & [10] & $E G, E P M, P$ & $R V, D$ & CB, Pstrl & $\mathrm{DL}, \mathrm{EG}, \mathrm{CDW}, \mathrm{AA}$ & Yes \\
\hline 5 & {$[12]$} & $E G, E P M, G, P D$ & $R V, D$ & CW & 0 & Yes \\
\hline 6 & {$[11]$} & $E G, G$ & $\mathrm{RV}, \mathrm{W}$ & CW & AA & Yes \\
\hline 7 & [13] & $E G, G$ & RV, W & CW & IMA, EG, RP, AA & Yes \\
\hline 8 & [14] & G & $\mathrm{D}$ & Pstrl & 0 & Yes \\
\hline 9 & {$[17]$} & $P$ & W & CW & 0 & Yes \\
\hline 10 & {$[15]$} & G, Geo & $R V, W, D$ & CW & 0 & No \\
\hline 11 & [18] & EG, EPM & RV & CB, Pstrl & 0 & Yes \\
\hline 12 & {$[22]$} & $E G, G$ & RV & Com & $\mathrm{DL}$ & Yes \\
\hline 13 & [23] & $\mathrm{EG}, \mathrm{G}$ & RV & Com & IMA, G & Yes \\
\hline 14 & {$[25]$} & $E G, G$ & $\mathrm{RV}, \mathrm{W}$ & CB, Pstrl & 0 & Yes \\
\hline 15 & {$[27]$} & $E G, G$ & $R V, W, D$ & Com & G, SG & Yes \\
\hline 16 & {$[30]$} & EPM & $\mathrm{RV}, \mathrm{W}$ & Pstrl & $D L, I M A, A A$ & Yes \\
\hline 17 & {$[31]$} & G & $\mathrm{RV}, \mathrm{V}$ & Pstrl & $\mathrm{EG}, \mathrm{G}, \mathrm{SE}$ & Yes \\
\hline 18 & {$[37]$} & EG, G, Geo & W & CB, Pstrl & 0 & No \\
\hline 19 & {$[36]$} & $\mathrm{EG}, \mathrm{EPM}, \mathrm{G}, \mathrm{Geo}$ & RV, W & $\mathrm{ID}$ & 0 & Yes \\
\hline 20 & {$[41]$} & $E G, G$ & $\mathrm{D}$ & CB, Pstrl, U & G & Yes \\
\hline 21 & {$[42]$} & $P$ & RV & CW, Com & G, SE & No \\
\hline 22 & {$[44]$} & Mal & V & Com & 0 & Yes \\
\hline 23 & {$[47]$} & $E P M, P, G$ & W, D & Pstrl & $\mathrm{EG}, \mathrm{RM}, \mathrm{G}$ (local institutions), AA & Yes \\
\hline 24 & {$[54]$} & EPM & W & $C B$ & 0 & Yes \\
\hline 25 & [53] & $P, P D$ & W, D & Pstrl & 0 & No \\
\hline 26 & {$[58]$} & $E D, P, P D$ & $\mathrm{D}$ & $C B$ & $\mathrm{AA}$ & Yes \\
\hline \multirow[t]{2}{*}{27} & {$[60]$} & G & W & CB, Pstrl, U & G & Yes \\
\hline & \multicolumn{6}{|c|}{ Climate adaptation } \\
\hline 1 & {$[4]$} & 0 & W & $\mathrm{CB}$ & DC & No \\
\hline 2 & [7] & SE & $\mathrm{RV}, \mathrm{W}$ & $\mathrm{ID}$ & $D C, I E C, I C$ & Yes \\
\hline 3 & [19] & 0 & $\mathrm{RV}, \mathrm{W}$ & $C B$ & $\mathrm{Cl}, \mathrm{GM}$ & No \\
\hline 4 & {$[20]$} & SE & $\mathrm{RV}, \mathrm{W}$ & $C B, M C, M U$ & DC, Tech, IEC & Yes \\
\hline 5 & [21] & SE & $\mathrm{D}$ & U & ISD & Yes \\
\hline 6 & {$[28]$} & SE & $\mathrm{RV}, \mathrm{W}$ & $C B$ & $\mathrm{RWH}, \mathrm{Cl}$ & No \\
\hline 7 & [29] & 0 & $\mathrm{RV}, \mathrm{W}$ & $C B$ & RWH & No \\
\hline 8 & [32] & $\mathrm{SE}, \mathrm{LB}$ & RV & MU & 0 & No \\
\hline 9 & [33] & SE & $R V, W, D$ & $\mathrm{CB}$ & $D C$, ISD & Yes \\
\hline 10 & [34] & SE & $\mathrm{RV}, \mathrm{W}$ & $\mathrm{MU}$ & DC, Tech, IEC, IC & Yes \\
\hline 11 & {$[38]$} & SE & $\mathrm{D}$ & Pstrl & IMA, IEC & No \\
\hline 12 & {$[39]$} & SE & $R V, L D$ & CB, Pstrl & IC & Yes \\
\hline 13 & {$[46]$} & SE & $\mathrm{RV}, \mathrm{W}$ & CB, Pstrl & 0 & Yes \\
\hline 14 & {$[48]$} & $\mathrm{SE}, \mathrm{G}$ & W, D & CB, Pstrl & IC & Yes \\
\hline
\end{tabular}


Table 7 Final selection of articles ${ }^{\mathrm{a}}$ (Continued)

\begin{tabular}{lllllll}
\hline & Author & Non-climatic variables & Climatic variables & Group type/land use & Policy recommendations & Vulnerability assessed \\
\hline 15 & {$[49]$} & 0 & W, D & SC & DC, DL & Yes \\
16 & {$[50]$} & 0 & RV, W & CB, Pstrl, MU & MU (integrated farming) & Yes \\
17 & {$[51]$} & SE, FS & RV & CB & IEC, IC & Yes \\
18 & {$[56]$} & ID & RV & CB & Tech, IEC & Yes \\
19 & {$[59]$} & SE, G & RV, D & CB & DC, IEC & Yes
\end{tabular}

${ }^{a}$ Appendix A Key: Economic growth $=E G$, socio-economic $=S E$, food security $=F S$, ethno-political marginalization $=E P M$, poverty $=P$, population density $=P D$, governance $=\mathrm{G}$, geography (distance to settlements, boarders, roads) $=\mathrm{Geo}$, malnutrition $=$ Mal, livelihood based $=\mathrm{LB}$. Rainfall variability $=R \mathrm{RV}$, warming $=\mathrm{W}$, drought $=D$, land degradation $=L D$, vegetation (density change) $=V$, natural disasters $=N D$, extreme weather $=E W$. Crop based $=C B$, single $c$ rop $=S C$, mixed crop $=M C$, mixed use $=$ MU, pastoral (includes livestock for adaptation literature) $=$ Pstrl, civil war $=C W$, urban $=U$, communal $=$ Com, ill-defined $=I D$, not sufficiently analyzed $=0$. Diversify livelihoods $=D L$, increase market access $=I M A$, reduce poverty $=R P$, reduce marginalization $=R M$, stabilize governance $=S G$, conflict and disaster warning systems $=C D W$, agricultural adaptation $=A A$, diversify crops $=\mathrm{DC}$, increase farm assets and technology $=$ Tech, increase extension and credit services $=\mathrm{IEC}$, increase farm capacity $=\mathrm{IC}$, institutional development $=\mathrm{ISD}$, rainwater harvesting $=\mathrm{RWH}$, genetically modify $=\mathrm{GM}, \mathrm{crop}$ intensification $=\mathrm{Cl}$,

\section{Abbreviations}

PRIO: Peace Research Institute Oslo; SLR: Systematic Literature Review; UCDP: Upsala Conflict Data Program; UN: United Nations

\section{Acknowledgments}

Daniel Pearson would like to express his utmost gratitude to Professor Peter Newman, his Honours supervisor. Without his guidance and advice, this paper would not have seen fruition. Secondly, Mr. Pearson owes a debt of gratitude to Professor Greg Morrison for his advice and guidance as to the inner workings of the SLR methodology.

\section{Funding}

No funding was received or used in producing this paper.

\section{Availability of data and materials}

The datasets used and/or analysed during the current study are available from the corresponding author on reasonable request.

\section{Authors' contributions}

The review was conducted by DP, drafting and editing of the final manuscript was completed by DP and PN. Both authors read and approved the final manuscript.

\section{Ethics approval and consent to participate}

Not applicable.

\section{Consent for publication}

Not applicable.

\section{Competing interests}

The authors declare that they have no competing interests.

\section{Publisher's Note}

Springer Nature remains neutral with regard to jurisdictional claims in published maps and institutional affiliations.

Received: 24 September 2018 Accepted: 22 January 2019

Published online: 19 February 2019

\section{References}

1. Ackerman A. The Idea and Practice of Conflict Prevention. J Peace Res. 2003. https://doi.org/10.1177/0022343303040003006

2. Adams C, Ide T, Barnett J, Detges A. Sampling bias in climate-conflict research. Nat Clim Chang. 2018. https://doi.org/10.1038/s41558-018-0068-2.

3. Adano WR, Dietz T, Witsenburg K, Zaal F. Climate change, violent conflict and local institutions in Kenya's drylands. J Peace Res. 2012. https://doi.org/ 10.1177/0022343311427344.

4. Akumaga U, Tarhule A, Piani C, Traire B, Yusuf AA. Utilizing Process-Based Modelling to Assess the Impact of Climate Change on Crop Yields and
Adaptation Options in the Niger River Basin West Africa. Agron. 2018. https://doi.org/10.3390/agronomy8020011.

5. Benjaminsen TA, Alinon $K$, Buhaug $H$, Buseth JT. Does climate change drive land-use conflict in the Sahel? J Peace Res. 2012. https://doi.org/10.1177/ 0022343311427343.

6. Bob U, Bronkhorst S, Sala S. Climate change and conflict: Conflict-sensitive climate change adaptation in Africa. In: Bob U, Bronkhorst S, editors. Conflict-sensitive adaptation to climate change in Africa. Berlin. BWV. 2014; p. 27-55.

7. Bryan E, Temesgen TD, Glwadys GA, Claudia R. Adaptation to climate change in Ethiopia and South Africa: Options and constraints. Environ Sci Policy. 2009. https://doi.org/10.1016/j.envsci.2008.11.002.

8. Buhaug $\mathrm{H}$. Climate change and conflict: taking stock. Peace Econ Peace Sci Pub Pol. 2016; https://doi.org/10.1515/peps-2016-0034.

9. Buhaug $\mathrm{H}$. Climate not to blame for African civil wars. Proc Natl Acad Sci U S A. 2010. https://doi.org/10.1073/pnas.1005739107.

10. Buhaug H, Benjaminsen TA, Sjaastad E, Theisen OM. Climate variability, food production shocks, and violent conflict in Sub-Saharan Africa. Environ Res Lett. 2015;10:12. https://doi.org/10.1088/1748-9326/10/12/125015.

11. Buhaug $H$, Hegre $H$, Strand $H$. Sensitivity Analysis of Climate Variability and Civil War. 2010; PRIO Paper. Oslo: PRIO.

12. Buhaug $\mathrm{H}$, Theisen OM. On environmental change and armed conflict. In: Scheffran J, Brzoska M, Brauch HG, Link PM, Schilling J, editors. Climate Change, Human Seurity and Violent Conflict: Challenges for Societal Stability. Berlin: Springer; 2012. p. 43-56.

13. Burke MB, Miguel E, Satyanath S, Dykema JA, Lobell DA. Warming increases the risk of Civil War in Africa. Proc Natl Acad Sci U S A. 2009. https://doi.org/ 10.1073/pnas.0907998106.

14. Butler C, Gates S. African range wars: Climate, conflict and property rights. J Peace Res. 2012. https://doi.org/10.1177/0022343311426166.

15. Couttenier M, Soubeyran R. Drought and Civil War in Sub-Saharan Africa. Econ J. 2013. https://doi.org/10.1111/ecoj.12042.

16. Denyer D, Tranfield D. Producing a systematic review. In: Buchanan DA, Bryman A, editors. The Sage handbook of organizational research methods. Thousand Oaks: Sage Publications Ltd; 2009. p. 671-689.

17. Devitt C, Tol RSJ. Civil war, climate change, and development: A scenario study for sub-Saharan Africa. J Peace Res. 2012. https:/doi.org/10.1177/0022343311427417.

18. Fjelde $\mathrm{H}$, von Uexkull N. Climate triggers: Rainfall anomalies, vulnerability and communal conflict in Sub-Saharan Africa. Polit Geogr. 2012. https://doi. org/10.1016/j.polgeo.2012.08.004.

19. Guan K, Sultan B, Biasutti M, Baron C, Lobell DB. Assessing climate adaptation options and uncertainties for cereal systems in West Africa. Agric For Meteorol. 2016. https://doi.org/10.1016/j.agrformet.2016.07.021.

20. Hassan R, Nhemachena C. Determinants of African farmers' strategies for adapting to climate change: Multinomial choice analysis. Afric J Agric Res Econ. 2008; https://ageconsearch.umn.edu/record/56969.

21. Heath T, Parker A, Weatherhead K. Testing a rapid climate change adaptation assessment for water and sanitation providers in informal settlements in three cities in sub-Saharan Africa. Environ Urban. 2012 https://doi.org/10.1177/0956247812453540. 
22. Hedrix CS, Glaser SM. Trends and triggers: Climate change and civil conflict in sub-Saharan Africa. Polit Geogr. 2007. https://doi.org/10.1016/j.polgeo. 2007.06.006

23. Hendrix CS, Salehyan I. Climate change, rainfall, and social conflict in Africa. J Peace Res. 2012;49(1):35-50.

24. Ide T. Does environmental peacemaking between states work? Insights on cooperative environmental agreements and reconciliation in international rivalries. J Peace Res. 2018;55(3):351-365.

25. Ide T, Schilling J, Link JSA, Scheffran J, Ngaruiya G, Weinzierl T. On Exposure, vulnerability and violence: Spatial distribution of risk factors for climate change and violent conflicts across Kenya and Uganda. Polit Geogr. 2014. https://doi.org/10.1016/j.polgeo.2014.10.007

26. IPCC, 2014: Climate Change 2014: Impacts, Adaptation, and Vulnerability. Part A: Global and Sectoral Aspects. Contribution of Working Group II to the Fifth Assessment Report of the Intergovernmental Panel on Climate Change [Field, C.B., V.R. Barros, D.J. Dokken, K.J. Mach, M.D. Mastrandrea, T.E. Bilir, M. Chatterjee, K.L. Ebi, Y.O. Estrada, R.C. Genova, B. Girma, E.S. Kissel, A.N. Levy, S. MacCracken, P.R. Mastrandrea, and L.L. White (eds.)]. Cambridge University Press, Cambridge, United Kingdom and New York, NY, USA, 1132 pp.

27. Jones BT, Mattiacci E, Braumoeller BF. Food scarcity and state vulnerability: Unpacking the link between climate variability and violent unrest. J Peace Res. 2017. https://doi.org/10.1177/0022343316684662.

28. Kahsay GA, Hansen LG. The effect of climate change and adaptation policy on agricultural production in Eastern Africa. Ecol Econ. 2015. https://doi.org/ 10.1016/j.ecolecon.2015.11.016.

29. Lebel S, Fleskens L, Forster PM, Jackson LS, Lorenz S. Evaluation of In Situ Rainwater Harvesting as an Adaptation Strategy to Climate Change for Maize Production in Rainfed Africa. Water Resour Manag. 2015. https://doi. org/10.1007/s11269-015-1091-y.

30. Maystadt JM, Calderone M, You L. Local warming and violent conflict in North and South Sudan. J Econ Geogr. 2015. https://doi.org/10.1093/jeg/lbu033.

31. Meier $\mathrm{P}$, Bond $\mathrm{D}$, Bond J. Environmental influences on pastoral conflict in the Horn of Africa. Polit Geogr. 2007. https://doi.org/10.1016/j.polgeo.2007.06.001

32. Mertz O, Mbow C, Nielsen JO, Maiga A, Diallo D, Reenberg A, Diouf A, Barbier B, Moussa IB, Zorom M, Ouattara I, Dabi D. Climate factors play a limited role for past adaptation strategies in West Africa. Ecology and Soc. 2010; Retrieved from http://www.ecologyandsociety.org/vol15/iss4/art25/

33. Muller C, Waha K, Bondeau A, Heinke J. Hotspots of climate change impacts in sub-Saharan Africa and implications for adaptation and development. Glob Chang Biol. 2014. https://doi.org/10.1111/gcb.12586.

34. Nhemachena C, Hassan R, Chakwizira J. Analysis of determinants of farmlevel adaptation measures to climate change in Southern Africa. J Dev Agric Econ. 2014. https://doi.org/10.5897/JDAE12.0441.

35. O'Brien AM, Mc Guckin C. The systematic literature review method: trials and tribulations of electronic data base searching at doctoral level. London: SAGE; 2016.

36. O'Loughlin J, Linke AM, Witmer FDW. Effects of temperature and precipitation variability on the risk of violence in sub-Saharan Africa, 19802012. Proc Natl Acad Sci U S A. 2014. https://doi.org/10.1073/pnas. 1411899111

37. O'Loughlin J, Witmer FDW, Linke AW, Laing A, Gettelman A, Dudhia J. Climate variability and conflict risk in East Africa, 1990-2009. Proc Natl Acad Sci U S A. 2012. https://doi.org/10.1073/pnas.1205130109.

38. Oyekale AS. Impacts of Climate Change on Livestock Husbandry and Adaptation Options in the Arid Sahel Belt of West Africa: Evidence from a Baseline Survey. Asian J Anim Vet Sci. 2014. https://doi.org/10.3923/ajava. 2014.13.26.

39. Ozor N, Urama K, Mwangi W. Climate Change Vulnerability and the Use of Indigenous Technologies for Adaptation among Smallholder Farming Communities in sub Saharan Africa. J Agric Exten. 2012. https://doi.org/10. 4314/jae.v16i2.13.

40. I R, S. Huq, Y.A. Anokhin, J. Carmin, D. Goudou, F.P. Lansigan, B. OsmanElasha, and A. Villamizar, 2014: Adaptation needs and options. In: Climate Change 2014: Impacts, Adaptation, and Vulnerability. Part A: Global and Sectoral Aspects. Contribution of Working Group II to the Fifth Assessment Report of the Intergovernmental Panel on Climate Change [Field, C.B., V.R. Barros, D.J. Dokken, K.J. Mach, M.D. Mastrandrea, T.E. Bilir, M. Chatterjee, K.L. Ebi, Y.O. Estrada, R.C. Genova, B. Girma, E.S. Kissel, A.N. Levy, S. MacCracken, P.R. Mastrandrea, and L.L. White (eds.)]. Cambridge University Press, Cambridge, United Kingdom and New York, NY, USA, pp. 833-868.
41. Raleigh C, Choi HJ, Kniveton D. The Devil is the details: An investigation of the relationships between conflict, food price and climate across Africa. Glob Environ Change. 2015. https://doi.org/10.1016/j.gloenvcha.2015.03.005.

42. Raleigh C, Kniveton D. Come rain or shine: An analysis of conflict and climate variability. J Peace Res. 2012. https://doi.org/10.1177/0022343311427754.

43. Reuters staff. 2009. "Text: Obama's U.N speech on climate change." Reuters. https://www.reuters.com/article/us-climate-obama-text-sb/text-obamas-u-nspeech-on-climate-change-idUSTRE58L2PR20090922.

44. Rowhani P, Degomme O, Guha-Sapir D, Lambin EF. Malnutrition and conflict: the impacts of resource variability on human security. Clim Chang. 2010. https://doi.org/10.1007/s10584-010-9884-8.

45. Sakaguchi K, Varughese A, Auld G. Climate Wars? A Systematic Review of Empirical Analyses on the Links between Climate Change and Violent Conflict. Int Stud Rev. 2017. https://doi.org/10.1093/isr/vix022.

46. Scheffran J, Marmer E, Sow P. Migration as a contribution to resilience and innovation in climate adaptation: Social networks and co-development in Northwest Africa. Appl Geogr. 2012. https://doi.org/10.1016/j.apgeog.2011.10.002.

47. Schilling J, Akuno M, Scheffran J, Weinzierl T. On raids and relations: Climate Change, pastoral conflict and adaptation in north-western Kenya. In: Bob U, Bronkhorst S, editors. Conflict-sensitive adaptation to climate change in Africa. Berlin: BWV; 2014. p. 241-69.

48. Schilling J, Freier KP, Hertig E, Scheffran J. Climate change, vulnerability and adaptation in North Africa with focus on Morocco. Agric Ecosyst Environ. 2012. https://doi.org/10.1016/j.agee.2012.04.021.

49. Schroth $G$, Laderach P, Martinez-Valle Al, Bunn C, Jassogne L. Vulnerability to climate change of cocoa in West Africa: Patterns, opportunities and limits to adaptation. Sci Total Environ. 2016. https://doi.org/10.1016/j.scitotenv.2016.03.024.

50. Seo SN. A geographically scaled analysis of adaptation to climate change with spatial models using agricultural systems in Africa. J Agric Sci. 2011. https://doi.org/10.1017/S0021859611000293.

51. Shikuku KM, Winowiecki L, Twyman J, Eitzinger A, Perez JG, Mwongera C, Laderach P. Smallholder farmers' attitudes and determinants of adaptation to climate risks in East Africa. Clim Risk Manag. 2017. https://doi.org/10. 1016/j.crm.2017.03.001

52. Smith P., M. Bustamante, H. Ahammad, H. Clark, H. Dong, E. A. Elsiddig, H. Haberl, R. Harper, J. House, M. Jafari, O. Masera, C. Mbow, N. H. Ravindranath, C. W. Rice, C. Robledo Abad, A. Romanovskaya, F. Sperling, and F. Tubiello, 2014: Agriculture, Forestry and Other Land Use (AFOLU). In: Climate Change 2014: Mitigation of Climate Change. Contribution of Working Group III to the Fifth Assessment Report of the Intergovernmental Panel on Climate Change [Edenhofer, O., R. Pichs-Madruga, Y. Sokona, E. Farahani, S. Kadner, K. Seyboth, A. Adler, I. Baum, S. Brunner, P. Eickemeier, B. Kriemann, J. Savolainen, S. Schlömer, C. von Stechow, T. Zwickel and J.C. Minx (eds.)]. Cambridge University Press, Cambridge, United Kingdom and New York, NY, USA

53. Theisen OM. Climate clashes? Weather variability, land pressure, and organized violence in Kenya, 1989-2004. J Peace Res. 2012. https://doi.org/ 10.1177/0022343311425842.

54. Theisen OM, Holtermann $\mathrm{H}$, Buhaug $\mathrm{H}$. Climate Wars?: Assessing the Claim That Drought Breeds Conflict. Int Sec. 2011; doi.org/10.1162/ISEC_a_00065.

55. UNDP. 2018. "Conflict Prevention and Peacebuilding." The United Nations Development Program. http://www.undp.org/content/undp/en/home/ ourwork/democratic-governance-and-peacebuilding/conflict-preventionand-peacebuilding/.

56. Urama K, Ozor N. Agricultural Innovations for Climate Change Adaptation and Food Security in Western and Central Africa. J Agric Food Environ Exten. 2011. https://doi.org/10.4314/as.v10i1.68717.

57. Vivekananda J, Schilling J, Smith D. Climate resilience in fragile and conflicted affected societies: concepts and approaches. Dev Pract. 2014. https://doi.org/10.1080/09614524.2014.909384.

58. von Uexkull N. Sustained drought, vulnerability and civil conflict in SubSaharan Africa. Polit Geogr. 2014. https://doi.org/10.1016/j.polgeo.2014.10.003.

59. Waha K, Muller C, Bondeau A, Dietrich JP, Kurukulasuriya P, Heinke J, Campen HL. Adaptation to climate change through the choice of cropping system and sowing date in sub-Saharan Africa. Glob Environ Change. 2012. https://doi.org/10.1016/j.gloenvcha.2012.11.001.

60. Witmer FDW, Linke AM, O'Loughlin J, Gettelman A, Laing A. Subnational violent conflict forecasts for sub-Saharan Africa. 2015-65, using climate-sensitive models. J Peace Res. 2017. https://doi.org/10.1177/0022343316682064. 